ARTICLE

Received 6 Mar 2015 | Accepted 10 Sep 2015 | Published 12 Oct 2015

DOI: $10.1038 /$ ncomms9613

OPEN

\title{
FR171456 is a specific inhibitor of mammalian NSDHL and yeast Erg26p
}

Stephen B. Helliwell ${ }^{1}$, Shantanu Karkare ${ }^{1}$, Marc Bergdoll ${ }^{2}$, Alain Rahier ${ }^{2}$, Juliet R. Leighton-Davis ${ }^{1}$, Celine Fioretto ${ }^{1}$, Thomas Aust ${ }^{1}$, Ireos Filipuzzi ${ }^{1}$, Mathias Frederiksen ${ }^{1}$, John Gounarides ${ }^{3}$, Dominic Hoepfner ${ }^{1}$, Andreas Hofmann', Pierre-Eloi Imbert ${ }^{1}$, Rolf Jeker ${ }^{1}$, Richard Knochenmuss ${ }^{1}$, Philipp Krastel ${ }^{1}$, Anais Margerit ${ }^{1}$, Klaus Memmert ${ }^{1}$, Charlotte V. Miault ${ }^{1}$, N. Rao Movva ${ }^{1}$, Alban Muller ${ }^{1}$, Hans-Ulrich Naegeli ${ }^{1}$, Lukas Oberer ${ }^{1}$, Vivian Prindle ${ }^{4}$, Ralph Riedl', Sven Schuierer ${ }^{1}$, Jessica A. Sexton ${ }^{3}$, Jianshi Tao ${ }^{4}$, Trixie Wagner ${ }^{1}$, Hong Yin ${ }^{3}$, Juan Zhang ${ }^{1}$, Silvio Roggo", Stefan Reinker ${ }^{1} \&$ Christian N. Parker ${ }^{1}$

FR171456 is a natural product with cholesterol-lowering properties in animal models, but its molecular target is unknown, which hinders further drug development. Here we show that FR171456 specifically targets the sterol-4-alpha-carboxylate-3-dehydrogenase (Saccharomyces cerevisiae-Erg26p, Homo sapiens-NSDHL (NAD(P) dependent steroid dehydrogenase-like)), an essential enzyme in the ergosterol/cholesterol biosynthesis pathway. FR171456 significantly alters the levels of cholesterol pathway intermediates in human and yeast cells. Genome-wide yeast haploinsufficiency profiling experiments highlight the erg26/ERG26 strain, and multiple mutations in ERG26 confer resistance to FR171456 in growth and enzyme assays. Some of these ERG26 mutations likely alter Erg26 binding to FR171456, based on a model of Erg26. Finally, we show that FR171456 inhibits an artificial Hepatitis C viral replicon, and has broad antifungal activity, suggesting potential additional utility as an anti-infective. The discovery of the target and binding site of FR171456 within the target will aid further development of this compound.

\footnotetext{
${ }^{1}$ Novartis Institutes for BioMedical Research, Novartis Campus, Basel, $\mathrm{CH}-4056$, Switzerland. ${ }^{2}$ Institut de Biologie Moléculaire des Plantes, CNRS, Unité Propre de Recherche 2357, Strasbourg cedex 67083, France. ${ }^{3}$ Novartis Institutes for BioMedical Research, 250 Massachusetts Avenue, Cambridge, Massachusetts, 02139, USA. ${ }^{4}$ GNF, San Diego, California 92121, USA. Correspondence and requests for materials should be addressed to S.H. (email: stephen.helliwell@novartis.com).
} 
T he cholesterol biosynthesis pathway, also known as the mevalonate pathway, is an essential cellular pathway that generates cholesterol-a major component of the plasma membrane. It represents a complex but highly regulated pathway, with the enzyme 3-hydroxy-3-methylglutaryl-coenzyme A reductase (HMGCR) being the most tightly regulated component controlling entry into the cholesterol pathway ${ }^{1}$. Cholesterol plays an important role in maintaining the plasma membrane integrity and dysregulation of this pathway has been shown to be a major cause of cardiovascular disease, thus contributing to mortality and morbidity worldwide ${ }^{2}$.

To counter cholesterol pathway imbalances in human disease, many molecules have been developed that target sterol biosynthesis enzymes. Statins target HMGCR, bisphosphonates target farnesyl diphosphate synthase, zaragozic acid and quinuclidines (3-(biphenyl-4-yl)-3-hydroxyquinuclidine) target squalene synthase. Further down the pathway, allylamines target squalene epoxidase, azoles target lanosterol $14 \alpha$-demethylase, morpholines target sterol $\mathrm{C}_{8}-\mathrm{C}_{7}$ isomerase/sterol reductase and azasterol targets sterol 24-C-methyltransferase ${ }^{3-7}$. Statins have been extremely successful in treating hypercholesterolemia but a significant clinical population experience side effects that prevent continuous or further use ${ }^{8}$.

Most other sterol pathway inhibitors have proven to be unsuitable for widespread clinical application due to detrimental physiological side effects. A number of these agents target fungalspecific stages of the pathway and have found application as anti-fungals. However, their poor anti-fungal spectrum, and the development of resistance to these anti-fungal treatments limits their usefulness. There is thus a clinical need for inhibitors of other components of the cholesterol pathway.

Sterol-4- $\alpha$-carboxylate 3-dehydrogenase, decarboxylating (NSDHL; often referred to as $3 \beta$-hydroxysteroid dehydrogenase/C4 decarboxylase $[3 \beta \mathrm{HSD} / \mathrm{D}])$, is conserved amongst eukaryotes and lies in the cholesterol pathway. NSDHL is distal to lanosterol synthase, and catalyses $\mathrm{NAD}^{+}$-dependent oxidative decarboxylation of $4 \alpha$-carboxysterol intermediates involved in the C- 4 demethylation process of sterol precursors to produce the corresponding 3-keto, C-4-decarboxylated products ${ }^{9,10}$. The NSDHL equivalent in S. cerevisiae-Erg26p, encoded by the essential gene $E R G 26$, also acts in the lanosterol-distal section of the yeast ergosterol synthesis pathway ${ }^{11}$. 33HSD/D from Arabidopsis thaliana has been characterized and its enzymology has been studied ${ }^{12}$, and essential catalytic and binding residues have been identified ${ }^{12,13}$. According to a homology model and biochemical studies of the A. thaliana enzyme ${ }^{13}$, Tyr159 and Lys 163 are oriented near the $3 \beta$-hydroxyl group of the substrate and directly involved in the dehydrogenation process, while Arg326 forms an essential salt bridge with the $4 \alpha$-carboxyl group of the substrate. The Asp39 residue is thought to contact the hydroxyl groups of the adenosine-ribose ring of $\mathrm{NAD}^{+}$. These crucial residues are highly conserved across plant, fungal and mammalian enzymes.

This report describes the identification of the previously described natural product FR171456 (refs 14,15) using bioactivity guided fractionation directed by inhibition of a Hepatitis $\mathrm{C}$ viral (HCV) replicon assay ${ }^{16}$. We used a range of complementary methods in three organisms to demonstrate that FR171456 targets the Erg26p/NSDHL enzyme of the sterol biosynthesis pathway. This is the first compound known to inhibit this enzyme specifically, and therefore represents a useful tool for chemical biologists. Since FR171456 targets a previously untargeted node in the sterol pathway these results may spur the development of a novel class of compounds with utility in hypercholesterolemia or fungal infection ${ }^{17}$. This discovery is entirely consistent with the compound's effects on cholesterol in rats and rabbits ${ }^{14,15}$.

\section{Results}

Metabolomics suggests that FR171456 inhibits NSDHL. Bioactivity guided fractionation identified FR171456 with an $\mathrm{IC}_{50}$ of $6.3 \mathrm{nM}$ in a Huh-7 cell-based assay that measures HCV replicon activity ${ }^{16}$. Although potent in the replicon assay the compound did not affect the proliferation of the repliconcarrying Huh-7 cells at concentrations up to $4 \mu \mathrm{M}$ under these assay conditions (Fig. 1a). The compound did not affect the proliferation of two other mammalian cell lines, HepG2 and K562, except at very high concentration $(80$ and $36 \mu \mathrm{M}$, respectively). In a screen to profile compound activity against 503 cancer cell lines only five cell lines were sensitive to FR171456 at an $A_{\max }<50 \%$ and $\mathrm{IC}_{50}<5 \mu \mathrm{M}$ (Supplementary Fig. 1$)^{18}$.

FR171456 was previously identified as a compound that blocks cholesterol synthesis at or after the squalene synthesis step of the pathway ${ }^{14}$. Various stages in the lifecycle of HCV require a normally functioning cholesterol biosynthesis pathway ${ }^{19}$, suggesting that FR171456's effect on cholesterol synthesis is the reason why it scored in the $\mathrm{HCV}$ replicon assay. In an attempt to understand which sterol (and other) metabolites are altered by FR171456 a metabolite-profiling experiment was conducted using cells from the original replicon assay exposed to vehicle or four concentrations of FR171456 (Fig. 1c,f, Methods, supplementary Fig. 2). Peaks in the mass spectra with statistically significant differences in intensities between the high $(80 \mathrm{nM})$ and low $(0 \mathrm{nM})$ concentration samples were selected by $P$ values $<0.01$ (Student's $t$-test, Bonferroni corrected) and ranked by fold changes. Metabolite identities were assigned to those peaks whose $\mathrm{m} / \mathrm{z}$ ratio corresponds to the mass of known metabolites (Supplementary Table 1).

Analysis of the most significantly increased metabolite peaks in this set revealed one at $\mathrm{m} / \mathrm{z} 465.3339 \mathrm{Da}$ (Fig. 1c, Supplementary Table 1). This corresponds to the mass of the known substrate of NSDHL, $4-\beta$-methylzymosterol-4- $\alpha$-carboxylate ${ }^{11,20}$. The dosedependent increase in intensities of this peak is consistent with inhibition of the NSDHL enzyme. A second peak at 467.3496 could represent 3- $\beta$-hydroxy $4 \beta$-methyl $5 \alpha$-cholest-7-ene $4-\alpha-$ carboxylate, that differs from $4-\beta$-methylzymosterol-4- $\alpha$ carboxylate by two hydrogens (Supplementary Table 1). This may represent an alternative reduced form of the substrate for NSDHL that would not normally be produced by these cells, but accumulates on blockage of the biosynthetic flux by FR171456 treatment. Reviewing this dataset for other known sterols revealed that calcidiol $(\mathrm{m} / \mathrm{z}$ 401.3418), a cholesterol metabolite situated downstream of NSDHL, is decreased in a FR171456 dosedependent manner, consistent with a reduction of cholesterol synthesis (Fig. 1f). No other sterol masses could be unequivocally assigned. Consistent with this data are the interpretation that FR171456 inhibits sterol synthesis between NSDHL and Calcidol synthase in Huh-7 cells.

Interestingly, three additional metabolites were identified as increasing in a dose-dependent manner. The peak at $\mathrm{m} / \mathrm{z}$ 463.3183 may correspond to Pfaffic acid, but the other two masses, $m / z 489.3314$ and $m / z 1198.8982$ cannot be assigned. The accumulation of these peaks at doses that correspond well to the activity of the compound in the HCV replicon assay suggests that these metabolites are possibly linked to the cholesterol synthesis pathway, as this pathway has been implicated in replication of the HCV replicon ${ }^{19}$.

FR171456 is antifungal and inhibits ergosterol synthesis. FR171456 demonstrated broad antifungal activity in a growth culture turbidity assay with standard minimum inhibitory concentration $^{21,22}$, in the range of $9-144 \mu \mathrm{M}$ with Aspergillus terreus as the most susceptible species (Supplementary Table 2). To 
assess whether FR171456 had effects on fungal ergosterol synthesis similar to those in mammalian cells (ergosterol is the fungal/plant equivalent of cholesterol), ergosterol pathway intermediates were measured following labelling of C. albicans with ${ }^{13} \mathrm{C}$-glucose, ${ }^{13} \mathrm{C}$-acetate and treatment with increasing

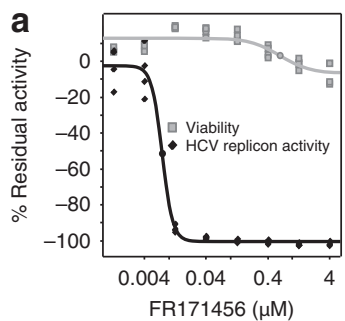

3-hydroxy-3-methylglutaryl-COA

b

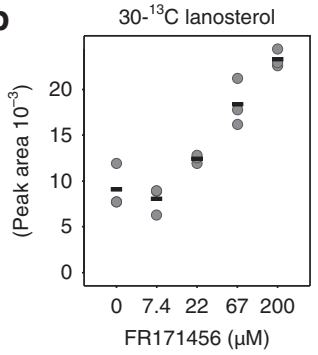

C
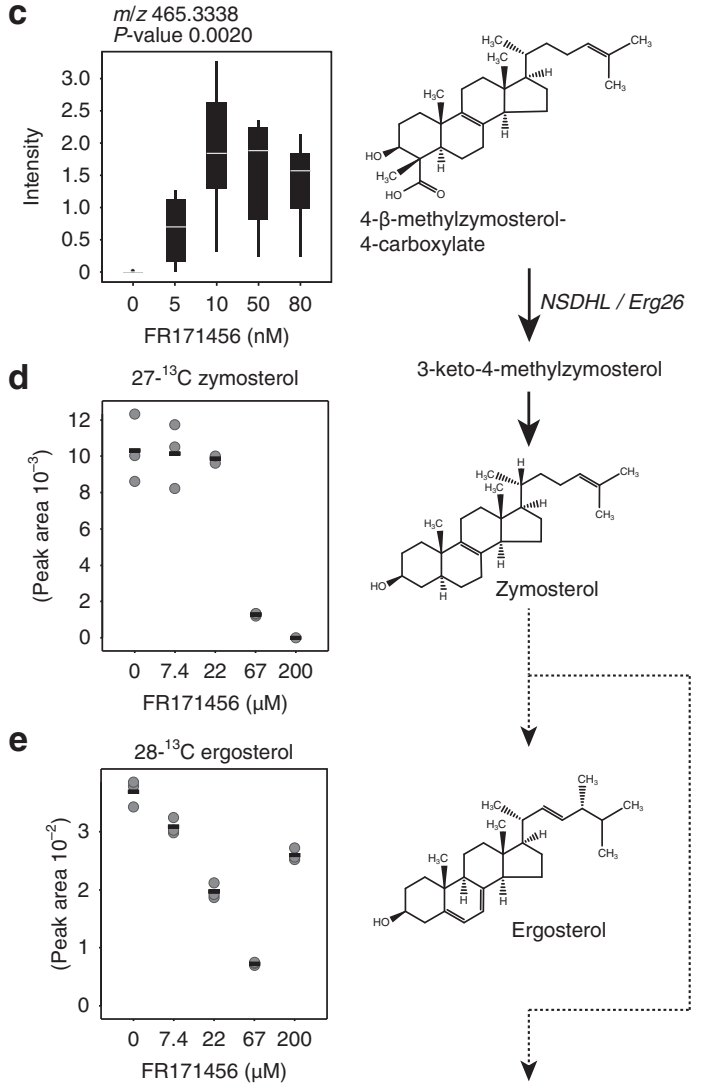

f

e
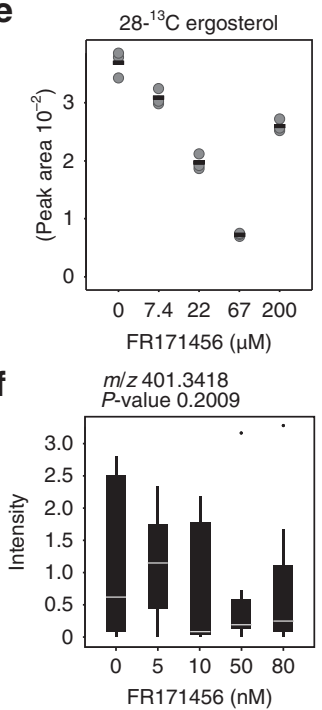

doses of FR171456 $(0-200 \mu \mathrm{M})$. The well-characterized Erg11p (Lanosterol 14- $\alpha$ demethylase) inhibitor fluconazole was used as a control (Supplementary Fig. 3). Consistent with its known activity, fluconazole caused an accumulation in ${ }^{13} \mathrm{C}$-labelled lanosterol and a decrease in both ${ }^{13} \mathrm{C}$-labelled zymosterol and ergosterol concentrations. FR171456 caused a dose-dependent reduction in zymosterol and ergosterol production, and an increase in lanosterol (Fig. 1b,d,e). At the highest tested concentration of FR171456, the amount of ${ }^{13} \mathrm{C}$-labelled ergosterol was increased compared with the vehicle control for reasons that are not clear. These data are consistent with the results from the mammalian cell metabolomics and previous work $^{14}$ and suggests that FR171456 inhibits a target downstream of lanosterol which may be NSDHL/Erg26p.

To further evaluate the potential use of FR171456 as an anti-fungal, we assessed FR171456 activity on $R$. oryzae and $F$. solani (clinical pathogens) in combination with two clinical antifungal agents, Posaconazole and Amphotericin B. No synergy was detected with posaconazole on either microbe, nor was it detected with Amphotericin B on R. oryzae (Loewe synergy score $<1$ in all three cases, data not shown). However, a small but significant effect was observed when treating $R$. oryzae with a combination of Amphotericin B and FR171456 (Supplementary Fig. 4), with a Loewe synergy score of 2.7 (where anything $>1$ is synergistic ${ }^{23}$ ). Interestingly, at several doses of FR171456 that alone are relatively ineffective $(6.67$ and $20 \mu \mathrm{M})$, the amount of Amphotericin B required for maximal inhibition is halved.

Genomic profiling identifies Erg26p as the FR171456 target. FR171456 inhibited growth of S. cerevisiae (BY4743 strain) with an $\mathrm{IC}_{50}$ of $14 \mu \mathrm{M}$, but neither FR171456 derivative (Compound 1, Compound 2, see Methods) demonstrated any significant growth inhibition at concentrations up to $200 \mu \mathrm{M}$ (Fig. 2a,b). Haploinsufficiency (HIP)/homozygous (HOP) profiling 24 was performed using FR171456 at a concentration that would cause a $30 \%$ inhibition $\left(\mathrm{IC}_{30}\right)$ of growth in a standard overnight culture (Fig. 2c). In the HIP profile, the ERG26 heterozygous strain (erg264/ERG26), shows the most significant hypersensitivity to FR171456. In addition, the SET6 heterozygote is also significantly hypersensitive. The SET6 strain often scores when profiling compounds that inhibit ergosterol synthesis in $S$. cerevisiae ${ }^{25}$. Erg26p functions in a complex with Erg25p and Erg27p (ref. 10), but strains heterozygous for ERG25 and ERG27 were indistinguishable from wild type in the HIP profile. This may suggest that Erg26p is the limiting factor in the enzyme complex, and also suggests high specificity of FR171456 for Erg26p. In addition, HIP and HOP was repeated using different concentrations of FR171456, revealing altered sensitivity of the ERG26 strain in a dose-dependent manner (Fig. 2d).

Figure 1 | FR171456 inhibits HCV replication and alters the levels of multiple sterol pathway intermediates. (a) The effect of increasing doses of FR171456 on Huh-7 human cell proliferation (grey symbols) and the HCV replicon (black symbols) were measured and plotted as a dose-response curve. (b-f) The sterol pathway is shown highlighting selected products/ substrates of pathway enzymes that could be detected as significantly altered in either Huh-7 cells treated for $48 \mathrm{~h}$ with increasing doses of FR171456 (c,f; black candlestick - bars and sticks represent 25/75th percentile and 1.58 times the interquartile range, respectively, from 15 separate measurements), or C. albicans cells treated with increasing doses of FR171456 for $14 \mathrm{~h} \mathrm{(b,d} \mathrm{and} \mathbf{e}$; grey circles and black bar represent the values and mean respectively from three biological replicates. 
Two homozygous diploid deletion strains demonstrated significant hypersensitivity to FR171456, YOR1 (yor14/yor14) and YPR090w (ypr090w $4 / y$ pr090w4). YOR1 encodes a known multidrug resistance pump for which FR171456 is likely a substrate. YPL090w encodes an ORF of unknown function whose deletion confers sensitivity to miconazole, an ergosterol synthesis

a
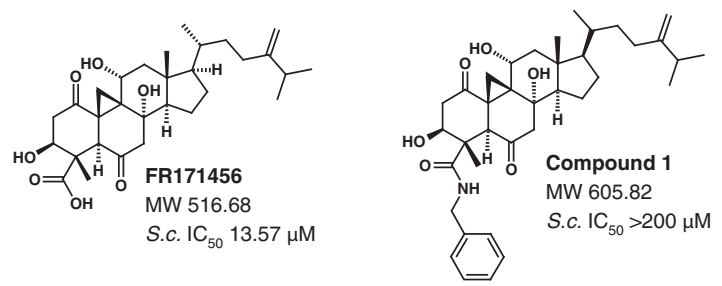

b Dose-responses
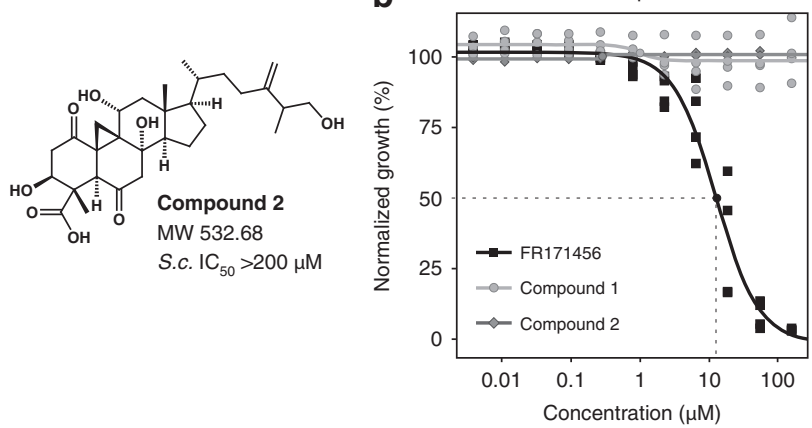

C

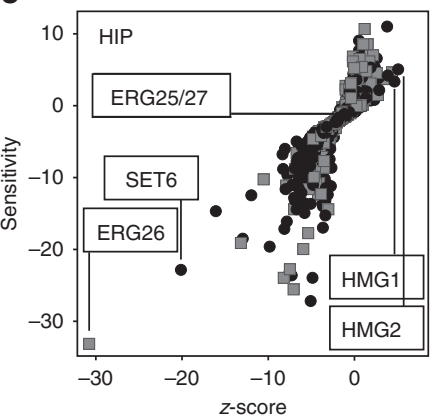

171456 $4 \mu \mathrm{M}$

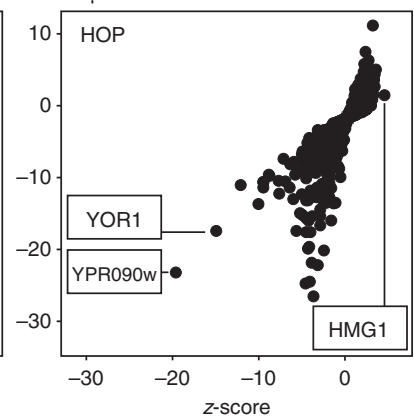

d
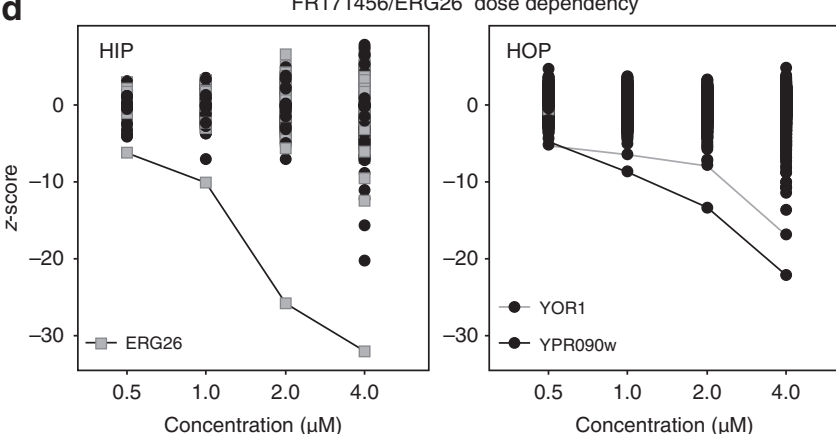

e

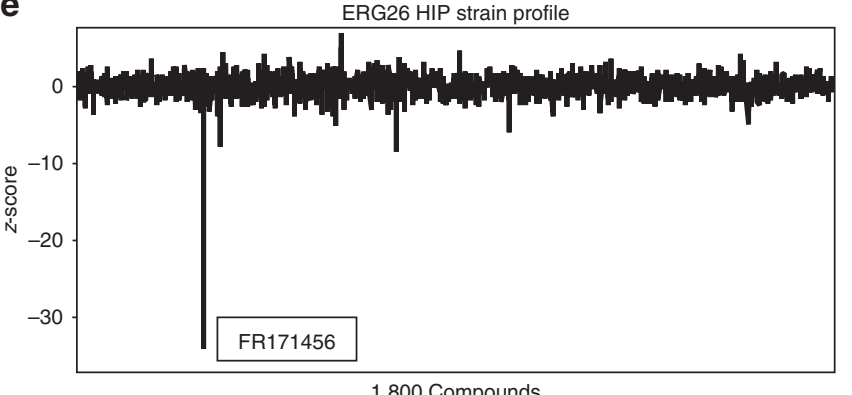

inhibitor, for reasons that are as yet unclear $^{26}$. HMG-CoA reductase catalyses the conversion of HMG-CoA to mevalonate, the rate-limiting step in sterol biosynthesis. Strains heterozygous for either one of the two genes encoding the yeast HMGCR (HMG1 and HMG2 ${ }^{27}$ ), and therefore carrying three out of four copies of HMGCR show weak but significant resistance to FR171456 (Fig. 2c). Furthermore, the HMG1 HOP strain carrying two from four copies of the HMGCR is also resistant (Fig. 2c). In these situations the effects of FR171456 are presumably partially remediated by a reduction in flux through the pathway, perhaps because an increase in sterol intermediate(s) between HMGCR and Erg26 is toxic.

Assessing the relative fitness of the ERG26 HIP strain across HIP profiles produced using 1,800 structurally unique compounds ${ }^{24}$ demonstrates that FR171456 is the only compound that has a significant effect on this strain (Fig. 2e). These results indicate that Erg26p is the major target of FR171456 in S. cerevisiae.

FR171456-resistant S. cerevisiae Erg26p mutants. The isolation of yeast mutants that confer resistance has been used to identify the target of novel compounds and their binding pockets ${ }^{28,29}$. In a semi-biased approach to identify critical sites on Erg26p that potentially interact with FR171456, we randomly mutagenized a haploid yeast strain lacking two major multidrug-resistance pumps and selected FR171456-resistant colonies on solid, rich, media containing FR171456 at a concentration that prevented wild-type colony formation $(50 \mu \mathrm{M})$. For 42 resistant clones, we sequenced only the ERG26 coding region-from these, 35 had single nucleotide alterations within ERG26. These mutations cause single-amino-acid changes in any one of only eight amino acids within the coding region of ERG26 gene (Supplementary Fig. 5, Supplementary Table 3). The other 7 resistant colonies were wild type for ERG26 and were not pursued further.

To confirm that the observed ERG26 mutations are dominant and sufficient to confer FR171456 resistance, but retain the essential function of Erg26p, we assessed the growth of erg264 haploid yeast expressing wild-type ERG26 or one of seven mutant alleles inserted at another locus in rich liquid media. All these mutations caused an increase in the $\mathrm{IC}_{50}$ compared with the isogenic control (Fig. 3a, Supplementary Fig. 6). It was not possible to generate a haploid strain carrying a single copy of ERG26 encoding the Gly90Ser mutation after multiple attempts. Thus seven of the eight mutations within the coding region of ERG26 are both dominant for FR171456 resistance and retain sufficient enzymatic function to support life. This additional genetic data set confirms that Erg26p is the target of FR171456.

Figure 2 | FR171456 targets Erg26p in S. cerevisiae. (a) Structures of FR171456, and two related triterpenes (compound 1, compound 2).

(b) Duplicate 12-point Dose response curves of wild-type diploid yeast with three compounds in a. Strain BY4743 was grown for $14 \mathrm{~h}$ at $30^{\circ} \mathrm{C}$ in YPD media with 2\% DMSO containing a dilution series of FR171456: black; Compound-1: light grey circles, and Compound-2: light grey squares. $Y$ axis: $\mathrm{OD}_{600}$ absorbance indicating yeast growth, $x$ axis: compound concentrations $(\log 10 \mu \mathrm{M})$. (c) Haploinsufficiency and homozygous profiling (HIP resp. HOP) for FR171456 at $4 \mu \mathrm{M}$. Each mutant strain in the pool is represented by a circle (non-essential genes) or a square (essential genes). The, $y$ axis represents strain sensitivity and $x$ axis represents $z$-score (specificity). In (d), the z-scores of the HIP pool strains ( $y$ axis) plotted against increasing doses of FR171456 ( $x$ axis; $\mu M$ ). (e) Relative compound sensitivity profile of the erg264/ERG26 strain across HIP experiments performed with 1,800 diverse small molecule yeast proliferation inhibitors. 


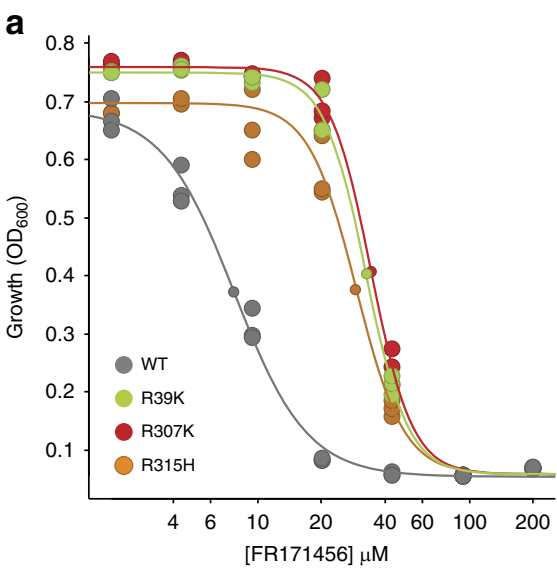

C

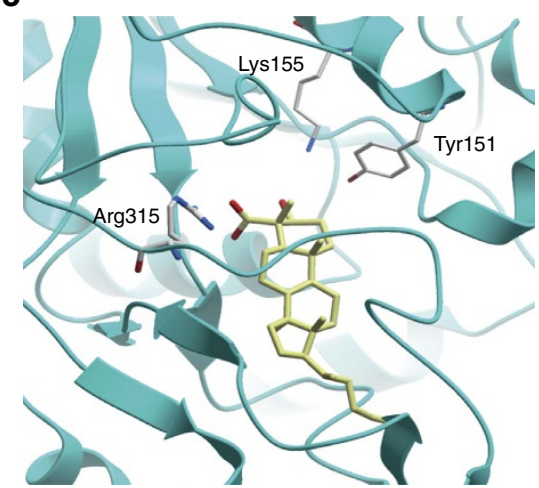

e

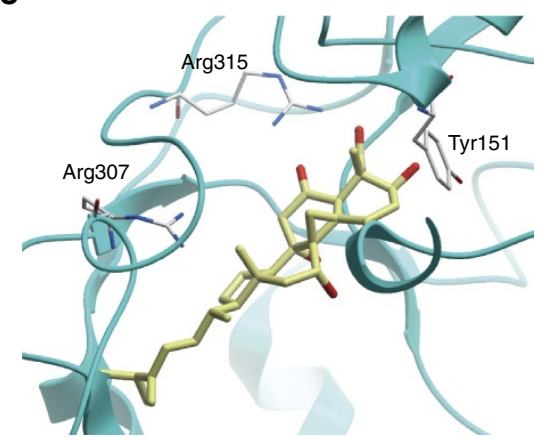

b

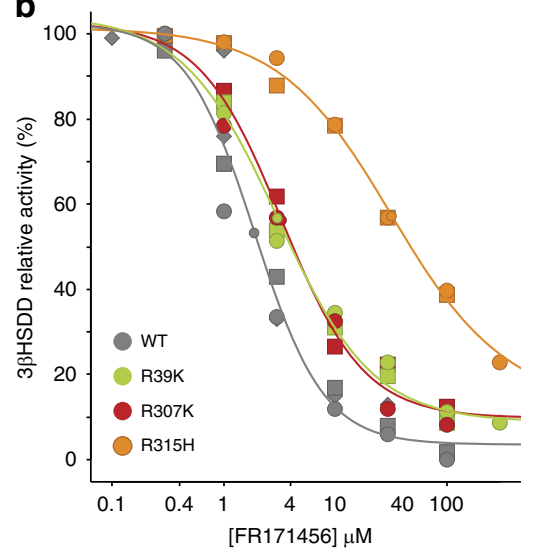

d

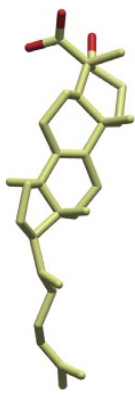

Substrate

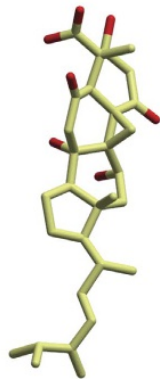

FR171456 f

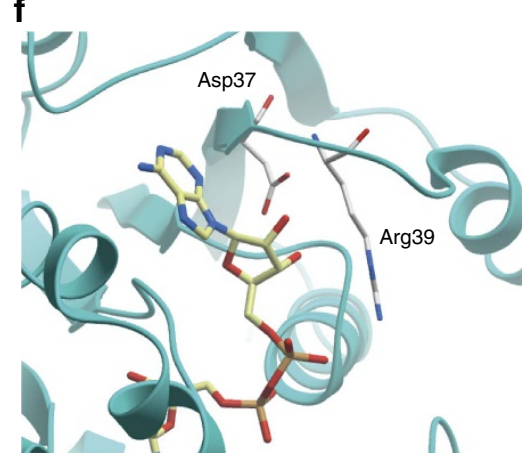

Figure 3 | FR171456 inhibits Erg26p in vitro (a) Dose-response curve for yeast haploid strains with single copy of ERG26 carrying single point mutations conferring resistance to FR171456 (see also Supplementary Fig. 6). Y axis: OD $_{600}$ absorbance indicating growth, $x$ axis: compound concentrations, dose response performed in triplicate. (b) FR171456 inhibits S. cereviasiae Erg26p enzyme activity as demonstrated by microsome-based biochemical assay, dose response performed in triplicate (wt) or duplicate (mutants). Y axis: relative reaction velocity compared with $A$. thaliana 3BHSDD, $x$ axis: FR171456 concentration. (c) Homology modeling of S. cerevisiae Erg26p with close up of active site with substrate and key interacting amino acids Tyr151, Lys155 and Arg315. (d) 3D structure of Erg26p substrate and FR171456 (see also Supplementary Fig. 9). (e) similar to (c) but with FR171456 docked, with Tyr151, Arg307 and Arg315 highlighted. Arg307Lys and Arg315His are changes giving resistance to FR171456 (f) Homology modelling of S. cerevisiae Erg26p with close up of NAD binding site with Arg37 and Arg39 highlighted. Arg39Lys mutants are FR171456 resistant.

FR171456 inhibits Erg26p enzymatic activity. Metabolic and genetic evidence suggests that Erg26p is the target of FR171456, presumably by directly inhibiting its enzymatic function. To test this hypothesis an in vitro microsomal Erg26p activity assay ${ }^{30}$ was used. Erg26p activity was directly assessed in the presence of increasing concentrations of FR171456 (10 nM-0.1 mM) in the presence of $150 \mu \mathrm{M}$ carboxysterol substrate (Fig. 1c) and the cofactor $\mathrm{NAD}^{+}(0.5 \mathrm{mM})$ followed by GC-MS detection of the product $4 \alpha$-methyl-cholest-8,24-dien-3-one. Figure. 3b shows that FR171456 strongly inhibits Erg26p activity in vitro. These results allowed the concentration of FR171456 required to reduce the reaction velocity to half $\left(I_{50}\right)$ to be determined: $I_{50}=2.2 \pm 0.5 \mu \mathrm{M}$.

$K_{\mathrm{m}}$ is an apparent dissociation constant for an enzymesubstrate complex and $\mathrm{K} i$ is the dissociation constant for an enzyme-inhibitor complex. The inhibition constant ( $\mathrm{K}_{\mathrm{i}}$ apparent) ${ }^{31}$ value for Erg26p/FR171456 was $1.35 \pm 0.3 \mu \mathrm{M}$ after fitting to a simple Michaelis-Menten mechanism inhibition equation. The $K_{\mathrm{m}}$ value of the carboxysterol substrate for the wild-type yeast Erg26p has been previously measured to be $550 \mu \mathrm{M}$ (ref. 32). The $I_{50} / K_{\mathrm{m}}$ ratio is used to compare the relative affinity towards the enzyme ${ }^{31}$, so FR171456 is a strong in vitro inhibitor of Erg26p 
with an approximate $I_{50} / K_{\mathrm{m}}$ ratio of $4 \times 10^{-3}$ for the carboxysterol substrate. Thus, this is the first reported in vitro enzyme activity that demonstrates that FR171456 has a high affinity for Erg26p and is a strong inhibitor of Erg26p.

Erg26p inhibition requires the $4 \alpha$-carboxyl group of FR171456. Previous work with $A$. thaliana $3 \beta \mathrm{HSD} / \mathrm{D}$ (NSDHL) indicates that the formation of an Arg326-substrate carboxylate salt bridge is required for productive binding of the substrate in the plant enzyme active site ${ }^{13}$. This is in accordance with the strict substrate specificity of the $3 \mathrm{bHSD} / \mathrm{D}$ that requires a free C-4 carboxyl group $^{12}$. The Erg26p equivalent of A. thaliana Arg326 is Arg315. Substitution of the $4 \alpha$-carboxylic group of FR171456 by a carbobenzylamido group (Compound-1) decreased inhibition by $>300$ fold $\left(I_{50}>0.5 \mathrm{mM}\right)$ confirming the requirement for the free C-4-carboxylic group for Erg26p inhibition by FR171456. This data suggests that this specific interaction is conserved between the plant and yeast enzymes.

FR171456 docking into homology model of S. cerevisiae Erg26p. In the absence of a crystal structure for S. cerevisiae Erg26p, or its human and plant homologues, a homology model of the enzyme was built based on the crystal structure of Pseudomonas aeruginosa UDP-N-acetylglucosamine 4-epimerase complexed with UDP-Nacetylgalactosamine (PDB ID: 1SB8) (Supplementary Fig. 8a). The homology model also shows conserved structural domains with three other templates in Protein Data Bank (Supplementary Fig. $8 \mathrm{~b}-\mathrm{d}$ ), but the 1SB8-derived model scored the best overall using multiple criteria (see Methods). To improve the accuracy of the model we determined the nuclear magnetic resonance (NMR) structure of the natural substrate following its purification from yeast inhibited with FR171456 (Methods, Fig. 3d, Supplementary Fig. 7).

The docked substrate and $\mathrm{NAD}^{+}$cofactor interactions with the $S$. cerevisiae Erg26p active site shown by the model were consistent with those previously determined in the case of the plant $A$. thaliana $3 \beta \mathrm{HSD} / \mathrm{D}$ (ref. 13; Fig 3c,f). These include the conserved catalytic Tyr151xxxLys155 motif proximal to the $3 \beta$-hydroxyl group of the carboxysterol, the Arg315 residue proximal to the $4 \alpha$-carboxylic group of the substrate, and the Asp37 residue bridging the two hydroxyl groups of the adenine ribose of $\mathrm{NAD}^{+}$in accordance with the $\mathrm{NAD}^{+}$versus $\mathrm{NADP}^{+}$ cofactor specificity. Note that Erg26p Arg315 is equivalent to Arg326 in A. thaliana, and forms a similar interaction with the carboxylic group of the substrate.

The X-ray and NMR structures of FR171456 were solved, indicating significant similarity between the inhibitor and the substrate (Fig. 3d, Supplementary Fig. 9, Table 1). Taking this into account, and the significance of the inhibitor $4 \alpha$-carboxylic group, FR171456 was docked in the carboxysterol binding pocket of S. cerevisiae Erg26p (Fig. 3e, Supplementary Fig. 10). The model suggests $3 \beta$-hydroxyl and $4 \alpha$-carboxyl interactions with Tyr151 and Arg315, polar interactions between the 6-oxo group of FR171456 and Cys312, the 1-oxo group and Ser86, and hydrophobic interactions between Phe 214 and the steroid nucleus of FR171456. Thus this model supports the hypothesis that FR171456 binds to Erg26p in the substrate-binding pocket.

Modelling FR171456 resistance mutations on Erg26p. The mutations that conferred resistance against FR171456, but remain functional as measured by yeast proliferation, were mapped onto the $S$. cerevisiae homology model. According to this model FR171456-resistant mutations are located as follows: Arg315His preserves the capacity of this catalytic residue to make a salt bridge with the substrate carboxyl group, preserving the catalytic

\section{Table 1 | Crystal data and structure refinement for FR171456.}

\begin{tabular}{|c|c|}
\hline Empirical formula & $\mathrm{C}_{31} \mathrm{H}_{48} \mathrm{O}_{8}$ \\
\hline Formula weight & 548.69 \\
\hline Temperature & $100(2) \mathrm{K}$ \\
\hline Wavelength & $1.54178 \AA$ \\
\hline Crystal system & Monoclinic \\
\hline Space group & P21 \\
\hline \multirow[t]{3}{*}{ Unit cell dimensions } & $a=7.447(2) \AA$ \\
\hline & $b=10.193(2) \AA$ \\
\hline & $c=19.229(3) \AA$ \\
\hline Volume & $1,439.1(5) \AA^{3}$ \\
\hline$Z$ & 2 \\
\hline Density (calculated) & $1.266 \mathrm{~g} \mathrm{~cm}^{-3}$ \\
\hline Absorption coefficient & $0.730 \mathrm{~mm}^{-1}$ \\
\hline $\mathrm{F}(000)$ & 596 \\
\hline Crystal size & $0.30 \times 0.18 \times 0.09 \mathrm{~mm}^{3}$ \\
\hline Theta range for data collection & $2.33-68.20^{\circ}$ \\
\hline Index ranges & $\begin{array}{c}-8 \leq h \leq 8,-11 \leq k \leq 10 \\
-23 \leq 1 \leq 23\end{array}$ \\
\hline Reflections collected & 44,812 \\
\hline Independent reflections & $5,008[R($ int $)=0.0347]$ \\
\hline Completeness to theta $=68.20^{\circ}$ & $99.3 \%$ \\
\hline Absorption correction & Semi-empirical from equivalents \\
\hline Max. and min. transmission & 0.9372 and 0.8108 \\
\hline Refinement method & Full-matrix least-squares on $\mathrm{F}^{2}$ \\
\hline Data/restraints/parameters & $5,008 / 13 / 399$ \\
\hline Goodness-of-fit on $F^{2}$ & 1.048 \\
\hline Final $\mathrm{R}$ indices $(I>2 \operatorname{sigma}(I))$ & $\mathrm{R} 1=0.0276, w R 2=0.0704$ \\
\hline $\mathrm{R}$ indices (all data) & $\mathrm{R} 1=0.0279, w R 2=0.0708$ \\
\hline Absolute structure parameter & $0.06(10)$ \\
\hline Largest difference peak and hole & 0.168 and -0.177 e. $\AA^{-3}$ \\
\hline
\end{tabular}

activity of $S$. cerevisiae Erg26p, but presumably reducing the binding of FR171456. In the case of the human enzyme NSDHL, Arg315 is substituted by His, demonstrating that this functionally conservative mutation still allows productive binding of the carboxysterol substrate. A second conservative mutation also located in the active-site pocket, Arg307Lys, is also likely to retain a viable catalytic activity, but could perturb the FR171456 interactions with the active site (Fig. 3e).

Two proline mutations, Pro144Leu and Pro147Leu, are not located in the active site, although Pro147 is proximal to the catalytic Tyr151 residue. Pro147 is conserved in $P$. aeruginosa UDP- $N$-acetylglucosamine 4-epimerase complexed with UDP- $N$ acetylgalactosamine (1SB8). This could play a role in the global architecture of the active site, and possibly in differential accessibility of the substrate and inhibitor to their binding domain. The Arg39Lys mutation is located in the active-site pocket (Fig. 3f). This functionally conservative mutation is proximal to the 2-adenosine ribose hydroxyl groups and diphosphate group of $\mathrm{NAD}^{+}$, and as such likely affects $\mathrm{NAD}^{+}$ binding and indirectly the interactions of its nicotinamide amido group with FR171456, possibly reducing its affinity.

Thus many of the FR171456 resistance mutations were mapped close to the $\mathrm{NAD}^{+}$or the substrate-binding site. The presence of three active conservative mutations Arg39Lys, Arg307Lys, and Arg315His in proximity to $\mathrm{NAD}^{+}$and substrate-binding site are consistent with FR171456 binding the substrate-binding pocket thus inhibiting the enzymatic activity. To address this more directly, we tested microsome extracts from the $\operatorname{erg} 264$ haploid yeast strains expressing the Erg26p wild type, Arg39Lys, Arg307His and Arg315His mutants in increasing doses of FR171456 to assess Erg26p mutant activity (Fig. 3b). Whilst Arg39Lys and Arg307His shift the $I_{50} 2$-fold, Arg315His confers a 
20 -fold shift in $I_{50}$. This highlights the importance of the interaction between Arg315 and the carboxyl group of the substrate/inhibitor as one of the most critical in the Erg26p active site (Fig. 3c).

\section{Discussion}

One of the central challenges facing chemical biologists is to identify a small-molecule inhibitor for each individual function of all human proteins ${ }^{33}$. In this study, FR171456 was reidentified due to its inhibitory activity in a phenotypic assay for HCV replicon, purified and its structure solved. Results from metabolomics, biochemistry, yeast genetics, and protein/ inhibitor/substrate structure modelling, are all consistent with FR171456 specifically inhibiting yeast Erg26, and the mammalian homologue NSDHL, an enzyme distal to squalene synthase in the sterol biosynthesis pathway. This is the first identification of an inhibitor for Erg26p/NSDHL, and contributes to the collection of compounds targeting specific points/ nodes in the ergosterol/ cholesterol biosynthesis pathway. The availability of a small molecule inhibitor of this node for the first time allows the inhibition of a node of sterol synthesis for which null mutations are unviable in yeast or mammalian systems. Such a tool compound will be useful to dissect the sterol pathway postsqualene in detail and suggests that NSDHL could be a drugable node $^{34}$.

In addition to representing a specific and potent molecular probe for NSDHL function, this molecule demonstrates several lead-like properties, most significantly showing in vivo efficacy on the target pathway. Hatori et al treated rats at up to $10 \mathrm{mg} \mathrm{kg}^{-1}$ in short term experiments and showed a significant reduction in hepatic sterol synthesis even at doses as low as $0.1 \mathrm{mg} \mathrm{kg}^{-1}$, demonstrating a potent effect on the cholesterol pathway. Most importantly, these authors treated rabbits for 3 weeks, demonstrating a significant reduction in serum cholesterol already at the $0.001 \mathrm{mg} \mathrm{kg}^{-1}$ dose, with no adverse effects reported for this experiment even at doses up to $1 \mathrm{mg} \mathrm{kg}^{-1}$ (ref. 14). In addition, pharmacological profiling against a panel of 24 receptors/ enzymes identified only one target with significant binding, the delta-opioid receptor, where an $\mathrm{IC}_{50}$ of $100 \mathrm{nM}$ was observed in a radioligand competition assay. Thus FR171456 has reasonable chemical properties, efficacy and specificity in vitro, and efficacy in vivo with no adverse events reported in two rodent models, all key properties of a lead molecule.

It has been demonstrated previously that host lipid metabolism is important for the lifecycle of HCV for several reasons: (1) the low-density lipid (LDL) receptor is important for HCV entry; (2) the mevalonate pathway is required for HCV RNA replication; and (3) very low-density lipid (VLDL) is essential for co-secretion with virus particles ${ }^{35}$. The isolation of FR171456 in the HCV replicon assay provides further evidence that viral replication is modulated by host sterol and lipid metabolism ${ }^{19,36-39}$. Thus, FR17145 represents a potential starting point for novel anti HCV drugs, and NSDHL in turn a novel target.

The compound also exhibited reasonable antifungal activity against a wide spectrum of fungal species such as S. cerevisiae, $C$. albicans, $A$. fumigatus with minimum inhibitory concentration ${ }^{21,22}$ in a range from 4 to $64 \mu \mathrm{g} \mathrm{ml}^{-1}(9-144 \mu \mathrm{M})$. Although these values do not make FR171456 a particularly potent small molecule, mammalian cell proliferation is unaffected by FR171456 in almost 500 cell lines tested in vitro ${ }^{18}$. In addition, in the original report describing FR171456, rabbits were treated with efficacious doses for 14 days with no reported side effects ${ }^{14}$. Taken together these data raise the hope that there may be a reasonable therapeutic window in vivo for compounds that inhibit this node in the sterol synthesis pathway.
Mutations in the NSDHL gene cause the human syndrome CHILD (congenital hemidysplasia with ichthyosiform nevus and limb defects), a dominant X-linked, male lethal disorder ${ }^{40}$. In recessive heterozygote males, the syndrome causes unilateral ichthyosiform skin lesions and limb reduction defects-known as $\mathrm{CK}$ syndrome ${ }^{41}$. For these pathologies, it has been suggested that not only cholesterol deficiency, but also accumulation of methyl sterols and carboxysterols causes disease ${ }^{42}$. Using FR171456 to cause the accumulation of upstream intermediates in relevant model systems should help to clarify this hypothesis. Indeed, the Huh7 cell metabolomics performed here demonstrated the accumulation of known and novel molecules in a dosedependent manner, and the elucidation of the novel molecule structures may suggest mechanisms whereby NSDHL inhibition causes toxic intermediate accumulation.

\section{Methods}

Purification of FR171456. A strain of Monodictys Sp. (from the Novartis strain collection) was cultured in medium MP3-01.00 (20 $\mathrm{gl}^{-1}$ defatted soya, $20 \mathrm{gl}^{-1}$ D-Mannitol, $1 \mathrm{ml}$ active solution $\mathrm{Nr} 1901$, which contained $4 \mathrm{gl}^{-1} \mathrm{ZnSO}_{4} \cdot 7 \mathrm{H}_{2} \mathrm{O}$ ), $\left.0.1 \mathrm{gl}^{-1} \mathrm{H}_{3} \mathrm{BO}_{3}, 5 \mathrm{gl}^{-1} \mathrm{FeSO}_{4} .7 \mathrm{H}_{2} \mathrm{O}, 0.005 \mathrm{gl}^{-1} \mathrm{KI}\right), 1 \mathrm{gl}^{-1} \mathrm{CoCl}_{2}, 0.2 \mathrm{gl}^{-1}$ $\mathrm{CuSO}_{4} \cdot 5 \mathrm{H}_{2} \mathrm{O}, 2 \mathrm{gl}^{-1} \mathrm{MnCl}_{2} \cdot 4 \mathrm{H}_{2} \mathrm{O}, 1 \mathrm{gl}^{-1}\left(\mathrm{NH}_{4}\right)_{6}\left(\mathrm{Mo}_{7} \mathrm{O}_{2}\right)_{4} \cdot 4 \mathrm{H}_{2} \mathrm{O}$. The culture was started with a $2.5 \%$ inoculum of a preculture which had been grown for four days from a cryovial of the strain. A 2-1 culture was then cultured for 6 days at $24^{\circ} \mathrm{C}$ at 200 r.p.m. The broth was filtrated through Celite. The filter cake containing the mycelium was extracted with ethyl acetate resulting in $0.5 \mathrm{~g}$ of extract. The complete ethyl acetate extract was separated on a reversed phase column $(50 \times 200 \mathrm{~mm}$ column packed with Merck Lichrospher RP18, 12- $\mu \mathrm{m}$ particle size). The elution gradient was from $30 \%$ acetonitrile in water rising to $100 \%$ within $60 \mathrm{~min}$, the mobile phase contained $0.01 \%$ trifluoroacetic acid (TFA). Combined fractions resulted in $9.9 \mathrm{mg}$ of purified FR171476.

The structure of FR171476 was determined by infrared spectroscopy, mass spectroscopy (MS) and NMR spectroscopy. The structure has been previously reported $^{14}$. FR171456 can be described chemically as (1R,2aR,3R,5aR,5bS,7aR,8S, 9S,11aS,12aR)-1,5b,9-trihydroxy-2a,8-dimethyl-3-((R)-6-methyl-5-methyleneheptan2-yl)-7,11-dioxohexadecahydrocyclopenta[a]cyclopropa[e]-phenanthrene-8carboxylic acid.

A sample was analysed by $1 \mathrm{H}$ NMR (600 MHz, dimethyl sulfoxide (DMSO)-d6) $\delta$ p.p.m. $0.68(\mathrm{~s}, 3 \mathrm{H}) 0.89(\mathrm{~d}, J=6.59 \mathrm{~Hz}, 3 \mathrm{H}) 0.98-1.00(\mathrm{~m}, 6 \mathrm{H}) 1.00(\mathrm{~s}, 3 \mathrm{H})$ $1.07-1.16(\mathrm{~m}, 2 \mathrm{H}) 1.17-1.35(\mathrm{~m}, 4 \mathrm{H}) 1.37(\mathrm{~d}, J=5.85 \mathrm{~Hz}, 1 \mathrm{H}) 1.44-1.55(\mathrm{~m}, 1 \mathrm{H})$ $1.64(\mathrm{q}, J=9.03 \mathrm{~Hz}, 1 \mathrm{H}) 1.78-1.91(\mathrm{~m}, 3 \mathrm{H}) 1.93-1.99(\mathrm{~m}, 1 \mathrm{H}) 2.02-2.11(\mathrm{~m}, 2 \mathrm{H})$ $2.14-2.25(\mathrm{~m}, 2 \mathrm{H}) 2.32(\mathrm{dd}, J=16.83,8.78 \mathrm{~Hz}, 1 \mathrm{H}) 2.51(\mathrm{dd}, J=12.44,7.32 \mathrm{~Hz}, 1$ H) $2.83(\mathrm{dd}, J=16.83,7.32 \mathrm{~Hz}, 1 \mathrm{H}) 4.15(t, J=8.05 \mathrm{~Hz}, 1 \mathrm{H}) 4.21(\mathrm{~s}, 1 \mathrm{H}) 4.38$ (br. s., $1 \mathrm{H}) 4.51$ (d, $J=6.59 \mathrm{~Hz}, 1 \mathrm{H}) 4.64$ (s, $1 \mathrm{H}) 4.70$ (s, $1 \mathrm{H}) 4.97$ (br. s., $1 \mathrm{H}$ ) 5.23 (br. s., $1 \mathrm{H}$ ).

The absolute configuration of FR171456 has been identified by high resolution $\mathrm{X}$-ray structure determination. The structure of the compound is shown in Fig. 3d and Supplementary Fig. 9. X-ray data for FR171456 is available in Table 1. This is the first report of the absolute $3 \mathrm{D}$ structure of this compound.

Synthesis of compound 1. Compound $1[(1 \mathrm{R}, 2 \mathrm{aR}, 3 \mathrm{R}, 5 \mathrm{aR}, 5 \mathrm{bS}, 7 \mathrm{aR}, 8 \mathrm{~S}, 9 \mathrm{~S}, 11 \mathrm{aS}, 12 \mathrm{aR})$ N-benzyl-1,5b,9-trihydroxy-2a,8-dimethyl-3-((R)-6-methyl-5-methyleneheptan-2-yl)7,11-dioxohexadecahydrocyclopenta[a]cyclopropa[e]phenanthrene-8-carboxamide] was prepared as follows. To a solution of FR171456 (30 mg, $0.058 \mathrm{mmol})$, benzylamine $(4.45 \mu \mathrm{l}, 0.04 \mathrm{mmol}), 1$-hydroxy-7-azabenzotriazole (HOAt; $120 \mu \mathrm{l}, 0.06 \mathrm{mmol}$ ) in $2.5 \mathrm{ml} \mathrm{DMF}, \mathrm{EDC} . \mathrm{HCl}(12.6 \mathrm{mg}, 0.064 \mathrm{mmol})$ was added at room temperature. The reaction mixture was stirred for $2.5 \mathrm{~h}$ at room temperature. Since only partial conversion was observed, additional benzylamine $(4.45 \mu \mathrm{l}, 0.04 \mathrm{mmol})$, HOAt $(120 \mu \mathrm{l}$, $0.06 \mathrm{mmol})$ and EDC.HCl $(12.6 \mathrm{mg}, 0.064 \mathrm{mmol})$ were added to the reaction. After $16 \mathrm{~h}$ at room temperature the reaction mixture was diluted in $20 \mathrm{ml}$ of ethyl acetate and $5 \mathrm{ml}$ of water. The organic phase was extracted with saturated $\mathrm{NaHCO}_{3}$ $(2 \times 5 \mathrm{ml})$ and brine $(2 \times 5 \mathrm{ml})$, dried over $\mathrm{Na}_{2} \mathrm{SO}_{4}$, and subsequently evaporated under reduced pressure. The crude product was separated by RP-HPLC on Luna C18 stationary phase and a gradient of the eluents (water/0.1\% formic acid and acetonitrile $/ 0.1 \%$ formic acid). Fractions containing compound- 1 were combined, dried under reduced pressure and subsequently lyophilized to yield $9.4 \mathrm{mg}(26.7 \%)$ of compound-1. Agilent 1100 LCMS analysis, MS $+m / z=606.31$. NMR data were recorded at $26^{\circ} \mathrm{C}$ on a Bruker AV-I-600 or AV-III-600 spectrometer, using a $1.7 \mathrm{~mm}$ TXI cryoprobe. ${ }^{1} \mathrm{H}$ NMR (600 MHz, DMSO- $\left.d_{6}\right)$ : $1 \mathrm{H}$ NMR $(600 \mathrm{MHz}, \mathrm{DMSO}-\mathrm{d} 6)$ $\delta$ p.p.m. $0.69(\mathrm{~s}, 3 \mathrm{H}) 0.90(\mathrm{~d}, J=5.85 \mathrm{~Hz}, 3 \mathrm{H}) 1.00(\mathrm{dd}, J=6.50 \mathrm{~Hz}, 6 \mathrm{H}) 1.13$ $(\mathrm{d}, J=5.85 \mathrm{~Hz}, 2 \mathrm{H}) 1.15(\mathrm{~s}, 3 \mathrm{H}) 1.17-1.36(\mathrm{~m}, 4 \mathrm{H}) 1.39(\mathrm{~d}, J=5.85 \mathrm{~Hz}, 1 \mathrm{H})$ $1.45-1.57(\mathrm{~m}, 1 \mathrm{H}) 1.64(\mathrm{q}, J=9.51 \mathrm{~Hz}, 1 \mathrm{H}) 1.84(\mathrm{~d}, J=14.60 \mathrm{~Hz}, 1 \mathrm{H}) 1.86-1.92$ $(\mathrm{m}, 2 \mathrm{H}) 1.97(\mathrm{dd}, J=14.64,6.59 \mathrm{~Hz}, 1 \mathrm{H}) 2.02(\mathrm{~d}, J=19.03 \mathrm{~Hz}, 1 \mathrm{H}) 2.05-2.11$ $(\mathrm{m}, 1 \mathrm{H}) 2.16(\mathrm{~d}, J=18.30 \mathrm{~Hz}, 1 \mathrm{H}) 2.18-2.26(\mathrm{~m}, 1 \mathrm{H}) 2.35(\mathrm{dd}, J=16.47,8.42 \mathrm{~Hz}$, $1 \mathrm{H}) 2.45-2.55(\mathrm{~m}, 1 \mathrm{H}) 2.82(\mathrm{dd}, J=16.83,6.59 \mathrm{~Hz}, 1 \mathrm{H}) 4.11(\mathrm{t}, J=7.68 \mathrm{~Hz}, 1 \mathrm{H})$ $4.28(\mathrm{dd}, J=15.37,5.85 \mathrm{~Hz}, 1 \mathrm{H}) 4.41(\mathrm{~s}, 2 \mathrm{H}) 4.44(\mathrm{dd}, J=15.40,5.90 \mathrm{~Hz}, 1 \mathrm{H})$ 
$4.47(\mathrm{~d}, J=6.59 \mathrm{~Hz}, 1 \mathrm{H}) 4.66(\mathrm{~s}, 1 \mathrm{H}) 4.72$ (s, $1 \mathrm{H}) 5.01$ (br. s., $1 \mathrm{H}) 5.20$ (br. s., $1 \mathrm{H}$ ) $7.18-7.22(\mathrm{~m}, 1 \mathrm{H}) 7.28(\mathrm{t}, J=7.68 \mathrm{~Hz}, 2 \mathrm{H}) 7.40(\mathrm{~d}, J=7.32 \mathrm{~Hz}, 2 \mathrm{H}) 7.87$ $(\mathrm{t}, J=5.85 \mathrm{~Hz}, 1 \mathrm{H})$

Synthesis of compound 2. Compound $2[(1 \mathrm{R}, 2 \mathrm{aR}, 3 \mathrm{R}, 5 \mathrm{aR}, 5 \mathrm{bS}, 7 \mathrm{aR}, 8 \mathrm{~S}, 9 \mathrm{~S}, 11 \mathrm{a}-$ S,12aR)-1,5b,9-trihydroxy-3-((2R)-7-hydroxy-6-methyl-5-methyleneheptan-2-yl)2a,8-dimethyl-7,11-dioxohexadecahydrocyclopenta[a]cyclopropa[e]phenanthrene8-carboxylic acid] was prepared as follows. The biotransformation of FR171456 with the strain Nocardioides simplex ATCC 6946 was performed in 0.5-l flasks each containing $95 \mathrm{ml}$ liquid medium of $4 \mathrm{~g} / \mathrm{l} \mathrm{D}-(+)$-glucose, $10 \mathrm{gl}^{-1}$ malt extract, $4 \mathrm{gl}^{-1}$ yeast extract and distilled water $(\mathrm{pH} 7,5)$. Each flask of the main culture was inoculated with $5 \mathrm{ml}$ of the preculture and incubated for 2 days at $28^{\circ} \mathrm{C}, 220$ r.p.m. Solutions of FR1714556 (2.2 mg, mmol) in $4.4 \mathrm{ml}$ methanol and $10 \mathrm{ml}$ of $1 \mathrm{M}$ $\mathrm{KH}_{2} \mathrm{PO}_{4}$ were added to each of the 11 flasks. After incubation for three days at $28^{\circ} \mathrm{C} / 180$ r.p.m. the fermentations were stopped by adding $100 \mathrm{ml}$ isopropanol to each culture. The solvents were evaporated under reduced pressure and the remaining broth was lyophilized. The dry powder was suspended in water and extracted with ethyl acetate. The organic phase was dried over $\mathrm{Na}_{2} \mathrm{SO}_{4}$ and evaporated under reduced pressure, yielding $405 \mathrm{mg}$ of crude product. It contained the desired product based on HPLC analysis and no starting material was detected. The crude product was separated by preparative reverse phase chromatography using an Ascentis phenyl stationary phase and a gradient of the eluents (water/0.1\% formic acid and acetonitrile/ $1 \%$ water $/ 0.1 \%$ formic acid). Fractions containing compound- 2 were combined, dried under reduced pressure and subsequently lyophilized. The sample was separated again using the same method yielding $5 \mathrm{mg}$ of compound-2. Agilent 1100 LCMS analysis, $M S+m / z=479.3$, fragmentation of parent ion observed. $1 \mathrm{H}$ NMR $(600 \mathrm{MHz}, \mathrm{DMSO}-\mathrm{d} 6) \delta$ p.p.m. 0.66 (s, $3 \mathrm{H}) 0.87$ $(\mathrm{d}, J=6.24 \mathrm{~Hz}, 3 \mathrm{H}) 0.96(\mathrm{~d}, J=6.60 \mathrm{~Hz}, 3 \mathrm{H}) 0.98(\mathrm{~s}, 3 \mathrm{H}) 1.04-1.12(\mathrm{~m}, 1 \mathrm{H}) 1.15$ $(\mathrm{d}, J=5.87 \mathrm{~Hz}, 1 \mathrm{H}) 1.16-1.27(\mathrm{~m}, 3 \mathrm{H}) 1.28-1.33(\mathrm{~m}, 1 \mathrm{H}) 1.35(\mathrm{~d}, J=5.14 \mathrm{~Hz}$, $1 \mathrm{H}) 1.44-1.54(\mathrm{~m}, 1 \mathrm{H}) 1.57-1.65(\mathrm{~m}, 1 \mathrm{H}) 1.76-1.88(\mathrm{~m}, 3 \mathrm{H}) 1.94(\mathrm{dd}, J=14.67$, $6.60 \mathrm{~Hz}, 1 \mathrm{H}) 2.00-2.08(\mathrm{~m}, 2 \mathrm{H}) 2.13(\mathrm{dd}, J=12.84,6.97 \mathrm{~Hz}, 1 \mathrm{H}) 2.18(\mathrm{dd}$, $J=19.07,2.57 \mathrm{~Hz}, 1 \mathrm{H}) 2.30(\mathrm{dd}, J=17.24,8.80 \mathrm{~Hz}, 1 \mathrm{H}) 2.44-2.53(\mathrm{~m}, 1 \mathrm{H}) 2.80$ $(\mathrm{dd}, J=17.24,7.34 \mathrm{~Hz}, 1 \mathrm{H}) 3.18(\mathrm{ddd}, J=10.27,7.70,5.50 \mathrm{~Hz}, 1 \mathrm{H}) 3.41(\mathrm{dt}$, $J=10.36,5.27 \mathrm{~Hz}, 1 \mathrm{H}) 4.12(\mathrm{t}, J=7.89 \mathrm{~Hz}, 1 \mathrm{H}) 4.19(\mathrm{~s}, 1 \mathrm{H}) 4.36(\mathrm{~d}, J=2.57 \mathrm{~Hz}, 1$ H) $4.43(\mathrm{t}, J=5.32 \mathrm{~Hz}, 1 \mathrm{H}) 4.48(\mathrm{dd}, J=6.24,2.93 \mathrm{~Hz}, 1 \mathrm{H}) 4.67(\mathrm{~s}, 1 \mathrm{H}) 4.69(\mathrm{~s}, 1$ H) $4.97(\mathrm{~d}, J=2.93 \mathrm{~Hz}, 1 \mathrm{H}) 5.19$ (br. s, $1 \mathrm{H}) 11.89$ (br. s, $1 \mathrm{H}$ ). NMR data were recorded at $26^{\circ} \mathrm{C}$ on a Bruker AV-I-600 or AV-III-600 spectrometer, using a $1.7 \mathrm{~mm}$ TXI cryoprobe.

Isolation of compound 3 by Erg26p substrate purification. In the fermentation experiment, a single yeast colony was grown in $10 \mathrm{ml}$ YP with galactose (2\%) \& Raffinose (1\%) for $5 \mathrm{~h}(\mathrm{OD} 1.0)$ at $30^{\circ} \mathrm{C}$. An inoculum $(70 \mu \mathrm{l})$ from the same culture was used to inoculate $400 \mathrm{ml}$ YP-gal $(2 \%)+$ Raffinose $(1 \%)$. This culture was then grown overnight at $30^{\circ} \mathrm{C}$. The $\mathrm{OD}$ at this point was 0.7 . This culture was used to seed 20-1 fermenter maintained at $30^{\circ} \mathrm{C}$. When OD in the fermenter was 0.7 , then $1466 \mathrm{nM}\left(\mathrm{IC}_{80}\right)$ of FR171456 was added to the fermenter. The cell pellets $(3.8 \mathrm{~g})$ were harvested after $7 \mathrm{~h}$. Erg26p substrate $(1.95 \mathrm{mg})$ was obtained by lipid extraction with ethylacetate and methanol.

The extraction protocol included suspension of collected yeast cells in $250 \mathrm{ml}$ methanol: water mixture $(9: 1)$. The extract was defatted by extraction with $250 \mathrm{ml}$ cyclohexane yielding $2.8 \mathrm{~g}$ defatted extract. The defatted extract was then subjected to chromatograph with a Sephadex LH20 $(5 \times 100 \mathrm{~cm})$ column using methanol as the solvent. The fraction $(205 \mathrm{mg})$ containing the desired compound was then further purified using reversed phase HPLC with a $30 \times 250 \mathrm{~mm}$ Sunfire RP18 column $(5 \mu \mathrm{m})$. The column was developed using the following solvents (A: $0.03 \%$ formic acid, B: acetonitrile containing $0.03 \%$ formic acid). The column was first washed with a solution of $70 \% \mathrm{~B}$ for $5 \mathrm{~min}$ followed by a gradient from $70 \% \mathrm{~B}$ to $100 \% \mathrm{~B}$ in $25 \mathrm{~min}$ yielding in $1.1 \mathrm{mg}$ desired substrate.

$1 \mathrm{H}-\mathrm{NMR}$ was used to determine the structure of the substrate. The parameters for the instrument were: $660.13 \mathrm{MHz}$ frequency, PROBHD: $1.7 \mathrm{MM}$ CPTCI1, DMSO solvent, PULPPROG ZG30, TD 65536. The NMR data for the compound: ${ }^{1} \mathrm{H}$ NMR $\left(600 \mathrm{MHz}, \mathrm{DMSO}-d_{6}\right) \delta$ p.p.m. 0.55 (s, $\left.3 \mathrm{H}\right) 0.91$ $(\mathrm{d}, J=6.60 \mathrm{~Hz}, 3 \mathrm{H}) 0.92(\mathrm{~s}, 3 \mathrm{H}) 0.95(\mathrm{~s}, 3 \mathrm{H}) 0.97-1.03(\mathrm{~m}, 1 \mathrm{H}) 1.09-1.16(\mathrm{~m}, 1$ H) $1.21-1.25(\mathrm{~m}, 3 \mathrm{H}) 1.27-1.31(\mathrm{~m}, 3 \mathrm{H}) 1.31-1.39(\mathrm{~m}, 2 \mathrm{H}) 1.43-1.54(\mathrm{~m}, 4 \mathrm{H})$ $1.55(\mathrm{~s}, 3 \mathrm{H}) 1.63(\mathrm{~s}, 3 \mathrm{H}) 1.63-1.67(\mathrm{~m}, 1 \mathrm{H}) 1.73(\mathrm{dd}, J=12.62,0.91 \mathrm{~Hz}, 1 \mathrm{H})$ $1.78-1.87(\mathrm{~m}, 3 \mathrm{H}) 1.88-2.06(\mathrm{~m}, 5 \mathrm{H}) 3.70(\mathrm{dd}, v 10.98,3.66 \mathrm{~Hz}, 1 \mathrm{H}) 5.06$ $(\mathrm{t}, J=6.59 \mathrm{~Hz}, 1 \mathrm{H})$

HCV replicon inhibitor screening. The inhibitor screening was performed in 1,536-well plate with 3,000 cells per well, using Huh-7 cells containing the HCV replicon subgenomic genotype $1 \mathrm{~b}$, maintained in DMEM, supplemented with $(1 \times)$ L-glutamine (L-Glue), $1 \times$ non-essential amino acids, $10 \%$ heat-inactivated fetal bovine serum (FBS), and $1 \mathrm{mg} \mathrm{ml}^{-1} \mathrm{G} 418$, and incubated with compounds for $48 \mathrm{~h}$ at $37^{\circ} \mathrm{C}, 5 \% \mathrm{CO}_{2}$. Compounds or microbial extracts were diluted in $90 \%$ DMSO and then diluted in culture media so that the addition of $10 \mathrm{nl}$ of dilutant to the cells resulted in a final DMSO concentration of $0.18 \%$. Following compound incubation, Resazurin solution (10 $\times: 1 \mu \mathrm{g} \mu \mathrm{l}^{-1}$ Resazurin in DMSO) diluted to $1 \times$ was then added to a volume of $0.5 \mu \mathrm{l}$ to each well and incubated for further $3 \mathrm{~h}$ at $37^{\circ} \mathrm{C}, 5 \% \mathrm{CO}_{2}$ to monitor cell viability. Subsequently $15 \mu \mathrm{l}$, diluted 1:2 from stock of Steady- Glo (Promega) was added and the luminescence from the HCV replicon was monitored using the Envision (Envision US Lum, using $0.1 \mathrm{~s}$ per well measurement time).

Yeast strains and plasmids. BY4741 a pdr5::kanMX snq2::kanMX was constructed using standard techniques using strains obtained from Invitrogen (Cat no: 95400.BY4741); the heterozygous and homozygous deletion collections were also obtained from Invitrogen. pRS416 is a CEN URA3 shuttle vector. All cloning was performed using standard molecular biology techniques ${ }^{43}$.

For ${ }^{13} \mathrm{C}$ - labelling studies, the wild type C. albicans strain SC5314 was obtained from ATCC (Manassas, VA) and was cultured at $30^{\circ} \mathrm{C}$ in YPD broth ( $1 \%$ yeast extract, $2 \%$ peptone, $2 \%$ dextrose) or Synthetic Medium (3\% glycerol, $0.1 \%$ glucose, $65 \mathrm{mM} \mathrm{NH}_{4} \mathrm{Cl}, 1.7 \mathrm{mM} \mathrm{NaCl}, 7 \mathrm{mM} \mathrm{KH}_{2} \mathrm{PO}_{4}, 1 \mathrm{mM} \mathrm{CaCl}, 0.5 \mathrm{mM} \mathrm{MgSO}{ }_{4}$ ).

Mutagenesis. For EMS mutagenesis experiments, $1 \times 10^{8}$ cells were plated on one standard YPD agar plate containing $50 \mu \mathrm{M}$ FR171456 in 2\% DMSO v/v following a standard EMS mutagenesis protocol. After 2 days incubation at $30^{\circ} \mathrm{C} 48$ representative colonies were picked and retested in an overnight liquid assay for growth in YPD with or without $50 \mu \mathrm{M}$ FR171456 in 2\% DMSO v/v. Genomic DNA was prepared from 42 resistant clones ( + one wild type) and for each the entire ERG26 gene was sequenced following PCR amplification with high-fidelity polymerase. These mutations were then cloned with their native promoter into BYintURA and then transformed into BY4743 erg26::kanMX/ERG26 diploid yeast strain and processed to create haploid strains carrying the BYIntURA3 vector with wild type or mutant ERG26 in the erg26::KanMX background. The FR171456 dose response assay for the mutants was performed in a 96-well plate format as described ${ }^{24}$.

Mass spectrometric analysis for global metabolomics profiling. Samples of cell pellets containing $8 \times 10^{6}$ cells each were lysed and extracted with $300 \mu$ cold methanol $\left(-80^{\circ} \mathrm{C}\right)$ in ultrasonic bath for $10 \mathrm{~min}$ and subsequently agitated for $5 \mathrm{~min}$ before centrifugation at $10,000 \mathrm{~g}$ for $5 \mathrm{~min}$ at $4{ }^{\circ} \mathrm{C}$. The supernatants were removed and the remaining pellets were again extracted twice. The supernatants from three extractions were then combined and dried using a SpeedVac (Savant, Fisher Scientific Inc., USA) for $2 \mathrm{~h}$ without heating. The residues were resuspended in $200 \mu \mathrm{l}$ of $80 \% \mathrm{MeOH}$ and centrifuged to remove any non-dissolvable particles. Finally, $10 \mu \mathrm{l}$ of the supernatant was then diluted by factor $100 \mathrm{in} \mathrm{MeOH} / \mathrm{H}_{2} \mathrm{O}(1: 1)$ for mass spectrometric analysis.

The diluted sample $(100 \mu \mathrm{l})$ was infused directly into a LTQ-Orbitrap mass spectrometer (Thermo Fisher Scientific, USA) using a HTC PAL autosampler (CTC Analytics, Zwingen, Switzerland) at a flow rate of $18 \mu \mathrm{min}^{-1}$. A make-up flow, consisting of $70 \%$ ethanol and $0.1 \%$ formic acid, was delivered through a $\mathrm{T}$-piece at $15 \mu \mathrm{min}^{-1}$. Electrospray ionization and selected monitoring scan were applied. The total mass range $m / z \quad 100-2,000$ was segmented into 48 scan events with a width of mass window $m / z 50$ each. Mass resolution at $m / z 400$ was 100,000 .

Each sample was measured in triplicate in positive ionization mode in random order. For quality and instrument stability control, the samples were interspersed with test mix infusion and pooled samples. Blank spectra were also recorded and the observed mass peaks of solvent and impurities were then suppressed in subsequent analysis.

The measured raw spectra were imported with in-house software written in the Igor package (Wavemetrics Inc.) for alignment, peak detection, and integral normalization. The table of exact peak masses and intensities (Supplementary Data, file Supplementary Dataset 1) were exported into the statistical software R, version 2.15.1, for subsequent univariate statistics and pathway analysis. For peak identification, the KEGG database was searched for matches of the observed peaks with endogenous metabolite entries. Metabolite masses with adducts of $\mathrm{H}^{+}, \mathrm{Na}^{+}$, or $\mathrm{K}^{+}$were considered a hit and possible identity of a peak if the difference between its exact monoisotopic mass and the observed mass plus adducts was below 3 p.p.m.

Focused metabolomics in C. albicans. Approximately $1.25 \times 10^{8}$ C. albicans cells from a saturated YPD culture were inoculated into $100 \mathrm{ml}$ Synthetic Medium (SM) and grown at $30^{\circ} \mathrm{C}$ to an OD of 1.0. Cells were washed once in modified SM ( $25 \mathrm{mM} \mathrm{KPO}_{4} \mathrm{pH} 7.0$, with glucose omitted) and suspended to $5 \mathrm{OD}_{600}$ units per $\mathrm{ml}$ in modified SM.

Labelling reactions were performed in 12-ml glass tubes with PTFE-lined caps (Corning) and containing $1 \mathrm{ml}$ cell suspension ( $\sim 6 \times 10^{7}$ cells), $10 \mu \mathrm{l}$ DMSO or $10 \mu \mathrm{l}$ compound dissolved in DMSO, $12 \mu \mathrm{l} 1 \mathrm{M}$ D-Glucose $\left(\mathrm{U}^{-13} \mathrm{C} 6\right.$ glucose), and $10 \mu 11 \mathrm{M}\left(1,2^{-13} \mathrm{C} 2\right)$ sodium acetate (Cambridge Isotope Laboratories, Inc). Before LC-MS analysis, dried lipid extracts were dissolved in $500 \mu \mathrm{l}$ methanol, vortexed and sonicated for $10 \mathrm{~min}$.

Squalene, ergosterol, lanosterol and zymosterol were quantified using the tandem mass spectrometer API4000 triple quadrupole (AB Sciex) with atmospheric pressure chemical ionization (APCI), interfaced to an Agilent LC.

Labelling reaction and lipid quantification. Cells $\left(\sim 6 \times 10^{7}\right)$ and compounds were preincubated $15 \mathrm{~min}$ at $30^{\circ} \mathrm{C}$ (without shaking) before the addition of labelled 
substrates. Labelling was performed at $30^{\circ} \mathrm{C}$ with shaking for $4 \mathrm{~h}$. Reactions were stopped by adding $1 \mathrm{ml} 30 \% \mathrm{KOH}, 1 \mathrm{ml} 100 \%$ ethanol, and $0.2 \mathrm{ml} 2 \%$ pyrogallol. Samples were mixed and then heated at $80^{\circ} \mathrm{C}$ for $30 \mathrm{~min}$, then cooled to room temperature. Non-saponifiable lipids were extracted two times in petroleum ether, washed with water, dried under nitrogen gas and stored at $-80^{\circ} \mathrm{C}$

For compound calibration, $2 \mu \mathrm{M}$ solutions in $0.1 \%$ formic acid were directly infused into the mass spectrometer. Ergosterol, lanosterol and zymosterol undergo dehydration and their molecular species are detected as $\left[\mathrm{M}+\mathrm{H}-\mathrm{H}_{2} \mathrm{O}\right]^{+}$while squalene is detected as $[\mathrm{M}+\mathrm{H}]^{+}$. Supplementary Table 4 lists the multiple reaction monitoring parameters of the sterols and squalene, as well as the ${ }^{13} \mathrm{C}$ incorporated metabolites. The mass spectrometer source parameters are the following: $\mathrm{CUR}=40, \mathrm{GS} 1=60, \mathrm{NC}=4.5$. TEM $=450 \mathrm{CAD}=4$. A mobile phase of $0.2 \%$ formic acid in methanol and isocratic run at $0.4 \mathrm{ml} \mathrm{min}^{-1}$ was employed to separate the metabolites on a Waters XBridge C18 $3.5 \mu \mathrm{m} 2.1 \times 50 \mathrm{~mm}$ column. The run time was $4.5 \mathrm{~min}$.

Metabolic Profiling for substrate accumulation in S. cerevisiae. Lipid extracts from yeast cells were prepared as described as above. Ergosterol and $4 \alpha$-methylzymosterol-4-carboxylic acid were analysed on an UltiMate 3000 RS LC (Thermo Fisher Scientific, Waltham, MA, USA) coupled to a 4000 QTRAP (AB Sciex, Foster City, CA, USA), which was equipped with a ESI-Turbo Spray ion source (AB Sciex).

Chromatography was carried out on a Waters Acquity UPLC BEH C18, $1.7 \mu \mathrm{m}$, $1 \times 50 \mathrm{~mm}$ column (Waters, Milford, MA, USA) with a flow rate of $200 \mu \mathrm{min}^{-1}$ and a gradient from $30 \% \mathrm{~A}\left(\mathrm{H}_{2} \mathrm{O}\right.$ with $0.1 \%(\mathrm{v} / \mathrm{v})$ formic acid) and $70 \% \mathrm{~B}$ (acetonitrile with $0.1 \%$ (v/v) formic acid) to $2 \% \mathrm{~A}$ and $98 \% \mathrm{~B}$ in $3.5 \mathrm{~min}$. Solvent composition remained for $4 \mathrm{~min}$ at $2 \% \mathrm{~A}$ and $98 \%$ B before the column was reconditioned to $30 \% \mathrm{~A}$ and $70 \% \mathrm{~B}$. The total runtime for one analysis was $12 \mathrm{~min}$. To reduce ion source contaminations, a switch valve was used to direct the flow to waste for the first $3.5 \mathrm{~min}$ and the last $5.5 \mathrm{~min}$ of the LC method.

Ion source parameters and compound-dependent instrument parameters were optimized by infusing pure standard solutions of ergosterol and $4 \alpha$ methylzymosterol-4-carboxylic acid, respectively. Ergosterol was detected in positive ion mode by selected reaction monitoring (SRM) using the mass transitions $379.3\left[\mathrm{M}-\mathrm{H}_{2} \mathrm{O}+\mathrm{H}\right]^{+} \rightarrow 69.2$ and $379.3 \rightarrow 83.1$ and $4 \alpha-$ methylzymosterol-4-carboxylic acid was detected using the mass transitions 425.3 $\left[\mathrm{M}-\mathrm{H}_{2} \mathrm{O}+\mathrm{H}\right]^{+} \rightarrow$ 95.1, 425.3 $\rightarrow 109.1$ and $425.3 \rightarrow$ 159.1. All mass transitions were monitored for $65 \mathrm{msec}$ per SRM scan with a unit/unit resolution for Q1/Q3. Analyst 1.5.1 (AB Sciex) was used for data analysis and peaks were smoothed with the Savitzky-Golay algorithm with a smoothing half width of 3 points.

HIP-HOP assay. The HIP assay was performed in 24-well plates (Greiner 662102), with $1.6 \mathrm{ml}$ per well YPD. Experimental compounds were tested at $n=2$ within the same plate at or close to their $\mathrm{IC}_{30}$ concentration. Each plate contained two no drug controls, one positive control (Benomyl), 10 experimental compounds in duplicates and one contamination control that received no cells. A standard experiment was 4 plates per 40 experimental compounds processed robotically without human intervention. YPD per compound filled wells were inoculated with $\sim 250$ yeast cells per strain $\left(100 \mu \mathrm{l}\right.$ of a $1.5-\mathrm{OD}_{600}$ per $\mathrm{ml}$ culture) from an overnight log phase preculture to start the experiment (Supplementary Fig. 2). The plates were pipetted with a standard 96 pipettor head by providing tip boxes preconfigured with a special tip pattern. Plates were incubated for $16 \mathrm{~h}$ in a robotic shaking incubator at $30^{\circ} \mathrm{C} / 550$ r.p.m. allowing for $\sim 5$ doublings. $\sim 250$ yeast cells per strain $(120 \mu \mathrm{l}$ of a $1.2-\mathrm{OD}_{600}$ per $\mathrm{ml}$ culture) were subsequently transferred into a preconfigured 24-well plate that was stored in a robotic plate reservoir at $4{ }^{\circ} \mathrm{C}$ until $30 \mathrm{~min}$ prior to its use where it was prewarmed to $30^{\circ} \mathrm{C}$. Once inoculated the new plate was incubated at $30{ }^{\circ} \mathrm{C} / 550$ r.p.m. to allow the next five yeast generations (generation 6-10) and the plate containing the first five doubling cultures was stored at $4{ }^{\circ} \mathrm{C}$. This procedure was repeated two more times until the final plate containing the yeast with $\sim 20$ generations were stored at $4{ }^{\circ} \mathrm{C}$.

The HOP assay was performed similar to the HIP experiment but the duration was reduced to approximately five doublings and no dilutions were necessary. Before the experiment, aliquots of the HOP pool were thawed and recovered for $3 \mathrm{~h}$ in YPD. The robotic system inoculated the wells prefilled with YPD and compound at the onset of the experiment with $\sim 320$ yeast cells/strain $\left(110 \mu \mathrm{l}\right.$ of a $1.50-\mathrm{OD}_{600}$ per $\mathrm{ml}$ culture). Plates were incubated for $16 \mathrm{~h}$ in a robotic shaking incubator at $30^{\circ} \mathrm{C} / 550$ r.p.m. allowing for approximately five doublings and where then stored at $4{ }^{\circ} \mathrm{C}$.

By applying a fixed time per dilution scheme to the HIP-HOP assay and diluting entire plates at fixed times we have simplified the procedure and managed to get optimal throughput. Careful $\mathrm{IC}_{30}$ determination and compound potency normalization resulted in very homogenous growth behaviours of the cultures in the 24 wells per plate. After each HIP-HOP experiment, growth curves recorded during the experiment were analysed.

gDNA extraction, TAG amplification and hybridization. An aliquot of $5 \mathrm{OD}_{600}$ units of yeast per well from the HIP and HOP experiments were arrayed in 96-well plates, spun and the supernatant discarded. gDNA extraction was performed using the ChargeSwitch kit (Invitrogen \#18000) in a partially automated process. One hundred and fifty microlitres per well of Zymolyase buffer (2 U Zymolyase, $50 \mathrm{ng}$ RNase A, in $20 \mathrm{mM}$ DTT and $20 \mathrm{mM}$ Tris pH 7.5) were added and the cells were incubated at $37^{\circ} \mathrm{C} / 700$ r.p.m. for $45 \mathrm{~min}$. Three hundred microlitres per well lysis buffer (L18, Invitrogen) was added and the plate incubated at $56^{\circ} \mathrm{C} / 700$ r.p.m. for $30 \mathrm{~min}$. Two hundred microlitres per well ice-cold precipitation buffer (N2, Invitrogen) was added and the precipitate pelleted by centrifugation at $4^{\circ} \mathrm{C}$. The supernatant was saved to a new deep well plate (AB-0932, Abgene) suitable to lock onto the Invitrogen MagnaRack magnet and $40 \mu \mathrm{l}$ per well of predispersed ChargeSwitch magnetic beads were added. The plate was incubated at room temperature for $5 \mathrm{~min}$ followed by incubation on the MagnaRack for $5 \mathrm{~min}$ to pellet the beads. All supernatant was carefully aspirated. The deep well plate was removed from the MagnaRack and $500 \mu \mathrm{l}$ per well wash buffer (W12, Invitrogen) were added and mixed to disperse the beads. The washing was repeated three times and the wash buffer completely removed. Finally, $70 \mu \mathrm{l}$ of elution buffer (E6, Invitrogen) were added. The beads were resuspended by mixing and the plate incubated for $10 \mathrm{~min}$ at room temperature. The beads were pelleted for one last time by incubation on the magnet for $5 \mathrm{~min}$ and the supernatant (containing the gDNA) was transferred to a new plate. The TAG PCR amplification and GenFlex Tag16K v2 hybridization protocol was used as described ${ }^{24}$.

Processing of TAG16K $v 2$ data. The raw probe intensity values of the CEL are summarized and normalized to tag intensities. Tags with low intensity values in control samples are removed by computing an intensity value threshold based on the comparison of the correlation between the logarithmic intensity ratios for uptags and downtags across different intensity ranges. The tag intensities are then averaged to obtain a strain intensity value. To measure the relative abundance of each strain with respect to the averages of the control samples we compute $M A D$ logarithmic (MADL) scores for each compound/concentration combination. If we denote the logarithm of the ratio of the average intensity of the compound samples over the average intensity of the control samples as $r_{L}$, then the MADL $s_{L}$ score is given as $\left(r_{L}-\operatorname{med}\left(r_{L}\right)\right) / \mathrm{MAD}\left(r_{L}\right)$ where the median and MAD are computed over all strains in one sample. MADL scores can be viewed as robustly computed experiment-wise $z$-scores. We also compute the $t$-test $P$ value, $P$, between the two replicates for a compound and the four to eight control replicates as a measure of the variability of the compound and control sample intensities across the experiment. The final (adjusted) score $a_{L}$ is decreased for highly variable strains and computed as:

$$
a_{L}=\min (0.05 / p, 1) \cdot s_{L}
$$

Then, we compute gene-wise $z$-scores (across all experiments) which are based on a robust parametric estimation of gene variability allowing for up to $15 \%$ outliers. To do this we consider the adjusted MADL scores $\left(a_{1}, \ldots, a_{n}\right)$ of a strain over $n$ experiments. Usually, the z-score transformation of score $a_{i}$ is defined as $z_{i}=$ $\left(a_{i}-\bar{a}\right) / \sigma$ where $\bar{a}$ is the mean and $\sigma$ the s.d. of the values $a_{i}$. However, due to the special nature of the HIP-HOP data it is advantageous to introduce a number of changes to the computation of the adjusted MADL $z$-score transformation. Since an (adjusted) MADL score of zero indicates a relative growth rate of a strain in the compound treated sample that is equal to the relative growth rate of the strain in the untreated control, we set $\bar{a}=0$, for all strains. What remains is to estimate $\sigma$ as a measure of the variability of the strain which is described in the following.

In order to avoid biasing the computation of the s.d. of a strain profile we allow at most five entries of the same compound/concentration combination in the data set. The samples of the sixth or greater occurance are discarded. We normalize the positive and negative scores separately; that is, we treat the positive and the negative scores as the halves of two separate distributions (artificially creating two perfectly symmetric distributions in this way). In the following we only consider the negative scores. Let the profile of the negative scores of a gene be $\left(s_{1}, \ldots, s_{n}\right)$ where we assume that the scores are sorted in ascending order. We assume that the scores follow a normal distribution $N(\mu, \sigma)$. Note that since the distribution is perfectly symmetric around $0, \mu=0$; moreover, for each $i$, the expectation of the score $s_{i}$ is the $i /(2 n+1)$-quantile $q_{i}$ of the standard normal distribution $N(0,1)$ times $\sigma$. In other words, $s_{i} / q_{i}$ is an estimator $\hat{\sigma}_{i}$ for $\sigma$, for each $i$. These estimators are computed only for the indices $i$ in the interval $(0.15 n, 0.85 n)$, that is, we consider only the middle $70 \%$ of the data to estimate $\sigma$. We assume that the scores $s_{i}$ are drawn for a normal distribution only if the s.d. of the $\hat{\sigma}_{i}$ is at most 0.05 times the mean $\bar{\sigma}$ of $\hat{\sigma}_{i}$; in this case, the estimators $\hat{\sigma}_{i}$ are considered to be consistent and $\bar{\sigma}$ a good estimate of $\sigma$. If the s.d. is larger, we abandon the parametric approach and just set $\bar{\sigma}$ to be the s.d. of sample $\left(s_{1}, \ldots, s_{n},-s_{1}, \ldots,-s_{n}\right)$. The estimate $\bar{\sigma}$ of $\sigma$ obtained from the single-array data is used to compute the normalized $z$-score transformation $\left(a_{1} / \bar{\sigma}, \ldots, a_{n} / \bar{\sigma}\right)$ of the adjusted MADL scores $\left(a_{1}, \ldots, a_{n}\right)$.

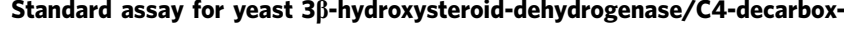
ylase. Wild-type yeast (FL200) microsomes were prepared as follows. Yeast cells were disrupted by glass bead homogenization $(0.45-\mathrm{mm}$ diameter) in $100 \mathrm{mM}$ phosphate buffer ( $\mathrm{pH}$ 7.5) containing $1.5 \mathrm{mM}$ reduced glutathione and $30 \mathrm{mM}$ nicotinamide for $8 \mathrm{~min}$ at $0{ }^{\circ} \mathrm{C}^{44}$. The cell extract was obtained by centrifugation at $10,000 \times \mathrm{g}$ for $20 \mathrm{~min}$. Microsomes were then isolated by centrifuging the cell extract supernatant at $100,000 \times \mathrm{g}$ for $90 \mathrm{~min}$. The resulting microsomal pellet was resuspended in $100 \mathrm{mM}$ phosphate buffer ( $\mathrm{pH} 7.5)$ containing $3 \mathrm{mM}$ reduced glutathione and $20 \%$ glycerol (v/v) using an Elvehjem-Potter homogenizer. Yeast microsomes ( $1.2 \mathrm{mg}$ of protein) were incubated in the presence of $4 \alpha$-carboxy- $4 \beta$ -

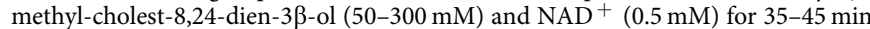
at $30^{\circ} \mathrm{C}$. After addition of coprostanone $(2-6 \mu \mathrm{g})$ as internal standard, the reactions were extracted as described previously ${ }^{12}$. The extract was analysed by TLC on silica 
gel and eluted twice with $\mathrm{CH}_{2} \mathrm{Cl}_{2}$. The fraction migrating between a standard of 4-desmethyl-sterone $\left(R_{\mathrm{F}}=0.50\right)$ and 4,4-dimethyl-sterone $\left(R_{\mathrm{F}}=0.70\right)$ was eluted and analysed using a GC-MS spectrometer (Agilent $5973 \mathrm{~N}$ ).

In the case of inhibition assays, microsomes were incubated for $35-45 \mathrm{~min}$ at $30^{\circ} \mathrm{C}$ in the presence of $4 \alpha$-carboxy- $4 \beta$-methyl-cholest- 8,24 -dien- $3 \beta$-ol $(50-300 \mathrm{mM})$ and a range of inhibitor concentration $(0.01-100 \mu \mathrm{M})$ from which a dose-response curve was obtained allowing the corresponding $\mathrm{I}_{50}$ values to be determined.

\section{GC-MS analysis for 3ß-hydroxysteroid-dehydrogenase/C4-decarboxylase} assay. The GC-MS spectrometer (Agilent $5973 \mathrm{~N}$ ) was equipped with an 'on column' injector and a capillary column $(30 \times 0.25 \mathrm{~mm})$ coated with DB5 $\left(\mathrm{H}_{2}\right.$ flow rate of $2 \mathrm{ml} \mathrm{min}^{-1}$ ). The temperature program included a $30{ }^{\circ} \mathrm{C} \mathrm{min}^{-1}$ increase from $60^{\circ} \mathrm{C}$ to $2400^{\circ} \mathrm{C}$, and followed by a $2^{\circ} \mathrm{C} /$ min increase from $240^{\circ} \mathrm{C}$ to $280^{\circ} \mathrm{C}$. The areas of the GC peaks of coprostanone $\left(t_{\mathrm{R}}=1.000\right)$ and of the produced $4 \alpha$-methyl-cholest-8,24-dien-3-one $\left(t_{\mathrm{R}}=1.139\right)$, corrected from endogenous component of the same $t_{\mathrm{R}}$ (1.139) determined in the blank (boiled microsomes), allowed the rate of transformation of $4 \alpha$-carboxy- $4 \beta$-methyl-cholest-8,24-dien-3 $\beta$ ol to be measured. Under these conditions, the estimated limit of detection of the $3 \beta \mathrm{HSD} / \mathrm{D}$ activity was $0.1 \mathrm{nmol} \mathrm{h}^{-1} \mathrm{mg}^{-1}$.

Molecular modelling. A homology model was produced by using $P$. aeruginosa $U D P-N$-acetylglucosamine 4-epimerase complexed with UDP-N-acetylgalactosamine and NAD $+(1 \mathrm{SB} 8)$ as a template, due to its highest primary sequence similarity (24\%) compared with all the other structures in PDB. The sequence alignment was performed by ClustalX ${ }^{45}$ and the homology model was constructed by MODELLER ${ }^{46}$. The model was then checked by QMEAN ${ }^{47}$ (http:// swissmodel.expasy.org/qmean/cgi/index.cgi).The structural comparison of the homology model with the other structures in the PDB was performed by DaliLite ${ }^{48}$ (http://www.ebi.ac.uk/Tools/structure/dalilite/). All the macromolecular figures were generated in PyMol (version 1.3; Schrödinger, LLC).

The QMEAN score and the $Z$-score for the model are 0.475 and -3.46 respectively. QMEAN score is global score for the whole model and reflects the predicted model reliability ranging from 0 to 127 . The QMEAN $Z$-score estimates the absolute quality of a homology model by relating it to reference structures solved by X-ray crystallography. These reference structures are a non-redundant subset of the PDB sharing less than 30\% pairwise sequence identity among each other and are solved at a resolution below than $2 \AA$. It is an estimate of the 'degree of nativeness' of the structural features observed in a model. The scores are not ideal because of the absence of any other closely related protein structures to compare with the structure used to build the model with $P$. aeruginosa UDP-N-acetylglucosamine 4-epimerase.

The homology model shows conserved structural domains with other templates in Protein Data Bank such as UDP-galactose 4-epimerase mutant (PDB ID: 3AW9), Thermus thermophilus HB8 UDP-glucose 4-epimerase complex with NAD (PDB ID: 2P5U), DesIV from Streptomyces venezuelae with NAD and TYD bound (PDB ID: 1R66) (Supplementary Fig.3). The structural comparision of the homology model with the above-mentioned templates using DaliLit program generated Z-score. The Z-scores for these are 34.9 with $2.2 \mathrm{~A}^{\circ} \mathrm{RMSD}, 36.9$ with $1.7 \mathrm{~A}^{\circ} \mathrm{RMSD}$ and 37.1 with $1.8 \mathrm{~A}^{\circ}$ RMSD respectively.

\section{References}

1. Brown, M. S. \& Goldstein, J. L. Atherosclerosis. Scavenging for receptors. Nature 343, 508-509 (1990).

2. Kingwell, B. A., Chapman, M. J., Kontush, A. \& Miller, N. E. HDL-targeted therapies: progress, failures and future. Nat. Rev. Drug Discov. 13, 445-464 (2014).

3. Mercer, E. I. Inhibitors of sterol biosynthesis and their applications. Prog. Lipid Res. 32, 357-416 (1993).

4. Onyewu, C., Blankenship, J. R., Del Poeta, M. \& Heitman, J. Ergosterol biosynthesis inhibitors become fungicidal when combined with calcineurin inhibitors against Candida albicans, Candida glabrata, and Candida krusei. Antimicrob. Agents Chemother. 47, 956-964 (2003).

5. BarrettBee, K. \& Dixon, G. Ergosterol biosynthesis inhibition: A target for antifungal agents. Acta Biochim. Pol. 42, 465-479 (1995).

6. de Souza, W. \& Rodrigues, J. C. F. Sterol Biosynthesis pathway as target for anti-trypanosomatid drugs. Interdiscipl. Perspec. Infect. Dis. 2009, 642502 (2009).

7. Roemer, T. \& Boone, C. Systems-level antimicrobial drug and drug synergy discovery. Nat. Chem. Biol. 9, 222-231 (2013).

8. Lim, S., Oh, P. C., Sakuma, I. \& Koh, K. K. How to balance cardiorenometabolic benefits and risks of statins. Atherosclerosis 235, 644-648 (2014).

9. Baudry, K. et al. The effect of the erg26-1 mutation on the regulation of lipid metabolism in Saccharomyces cerevisiae. J. Biol. Chem. 276, 12702-12711 (2001).

10. Mo, C., Valachovic, M., Randall, S. K., Nickels, J. T. \& Bard, M. Protein-protein interactions among C-4 demethylation enzymes involved in yeast sterol biosynthesis. Proc. Natl Acad. Sci. USA 99, 9739-9744 (2002).
11. Gachotte, D., Barbuch, R., Gaylor, J., Nickel, E. \& Bard, M. Characterization of the Saccharomyces cerevisiae ERG26 gene encoding the C-3 sterol dehydrogenase (C-4 decarboxylase) involved in sterol biosynthesis. Proc. Natl Acad. Sci. USA 95, 13794-13799 (1998).

12. Rahier, A., Darnet, S., Bouvier, F., Camara, B. \& Bard, M. Molecular and enzymatic characterizations of novel bifunctional $3 \beta$-hydroxysteroid dehydrogenases/c-4 decarboxylases from Arabidopsis thaliana. J. Biol. Chem. 281, 27264-27277 (2006).

13. Rahier, A., Bergdoll, M., Génot, G., Bouvier, F. \& Camara, B. Homology modeling and site-directed mutagenesis reveal catalytic key amino acids of $3 \beta$-hydroxysteroid-dehydrogenase/C4-decarboxylase from Arabidopsis. Plant Physiol. 149, 1872-1886 (2009).

14. Hatori, H. et al. FR171456, a novel cholesterol synthesis inhibitor produced by Sporormiella minima no. 15604 - II. Biological activities. J. Antibiot. 57, 260-263 (2004).

15. Hatori, H. et al. FR171456, a novel cholesterol synthesis inhibitor produced by Sporormiella minima No. 15604 - I. Taxonomy, fermentation, isolation, physico-chemical properties. J. Antibiot. 57, 253-259 (2004).

16. Bartenschlager, R. Hepatitis $C$ virus replicons: potential role for drug development. Nat. Rev. Drug Discov. 1, 911-916 (2002).

17. Vanden Bossche, H., Marichal, P. \& Odds, F. C. Molecular mechanisms of drug resistance in fungi. Trends Microbiol. 2, 393-400 (1994).

18. Barretina, J. et al. The Cancer Cell Line Encyclopedia enables predictive modelling of anticancer drug sensitivity. Nature 483, 603-607 (2012).

19. Scheel, T. K. H. \& Rice, C. M. Understanding the hepatitis C virus life cycle paves the way for highly effective therapies. Nat. Med. 19, 837-849 (2013).

20. Baudry, K. et al. The effect of the erg26-1 mutation on the regulation of lipid metabolism in Saccharomyces cerevisiae. J. Biol. Chem. 276, 12702-12711 (2001).

21. CLSI. Reference Method For Broth Dilution Antifungal Susceptibility Testing Of Filamentous Fungi; Approved Standard 2nd edn. (CLSIdocument M38-2A, 2008).

22. CLSI. Reference Method For Broth Dilution Antifungal Susceptibility Testing of Yeasts; Approved Standard 3rd edn. (CLSIdocument M27-A3, 2008).

23. Lehar, J. et al. Synergistic drug combinations tend to improve therapeutically relevant selectivity. Nat. Biotechnol. 27, 659-666 (2009).

24. Hoepfner, D. et al. High-resolution chemical dissection of a model eukaryote reveals targets, pathways and gene functions. Microbiol. Res. 169, 107-120 (2014).

25. Hoepfner, D. et al. An integrated approach for the identification and target validation of anti-fungal compounds active against Erg11p. Antimicrob. Agents Ch. 56, 4233-4240 (2012).

26. Thevissen, K. et al. Miconazole induces changes in actin cytoskeleton prior to reactive oxygen species induction in yeast. J. Biol. Chem. 282, 21592-21597 (2007).

27. Basson, M. E., Moore, R. L., Orear, J. \& Rine, J. Identifying mutations in duplicated functions in Saccharomyces cerevisiae-recessive mutations in HMG-CoA reductase genes. Genetics 117, 645-655 (1987).

28. Ho, C. H. et al. A molecular barcoded yeast ORF library enables mode-ofaction analysis of bioactive compounds. Nat. Biotechnol. 27, 369-377 (2009).

29. Heitman, J., Movva, N. R. \& Hall, M. N. Targets for cell cycle arrest by the immunosuppressant rapamycin in yeast. Science 253, 905-909 (1991).

30. Rahier, A., Darnet, S., Bouvier, F., Camara, B. \& Bard, M. Molecular and enzymatic characterizations of novel bifunctional 3beta-hydroxysteroid dehydrogenases/C-4 decarboxylases from Arabidopsis thaliana. J. Biol. Chem. 281, 27264-27277 (2006).

31. Chou, A. C. \& Wilson, J. E. Rat brain hexokinase: glucose and glucose-6phosphate binding sites and C-terminal amino acid of the purified enzyme. Arch. Biochem. Biophys. 165, 628-633 (1974).

32. Rondet, S. Biosynthese des sterols: 4-Carboxy-sterol decarboxylases de plante superieure et de levure; identification, characterisation et purification. $P h D$ Thesis (University of Strasbourg, 1998).

33. Schreiber, S. L. Small molecules: the missing link in the central dogma. Nat. Chem. Biol. 1, 64-66 (2005).

34. Bautz, D. J., Broman, K. W. \& Threadgill, D. W. Identification of a Novel Polymorphism in X-Linked Sterol-4-alpha-carboxylate 3-dehydrogenase (Nsdhl) Associated with Reduced HDL Cholesterol Levels in I/LnJ Mice. G3(Bethesda) 3, 1819-1825 (2013).

35. Ye, J. Reliance of host cholesterol metabolic pathways for the life cycle of hepatitis C Virus. PLoS Pathog. 3, e108 (2007).

36. Lyn, R. K. et al. Direct imaging of the disruption of hepatitis C virus replication complexes by inhibitors of lipid metabolism. Virology 394, 130-142 (2009).

37. Rothwell, C. et al. Cholesterol biosynthesis modulation regulates dengue viral replication. Virology 389, 8-19 (2009).

38. Syed, G. H., Amako, Y. \& Siddiqui, A. Hepatitis C virus hijacks host lipid metabolism. Trends Endocrin. Met. 21, 33-40 (2010). 
39. Syed, G. H. \& Siddiqui, A. Effects of Hypolipidemic Agent Nordihydroguaiaretic Acid on Lipid Droplets and Hepatitis C Virus. Hepatology 54, 1936-1946 (2011).

40. Caldas, H. \& Herman, G. E. NSDHL, an enzyme involved in cholesterol biosynthesis, traffics through the Golgi and accumulates on ER membranes and on the surface of lipid droplets. Hum. Mol. Genet. 12, 2981-2991 (2003).

41. Herman, G. E. X-linked dominant disorders of cholesterol biosynthesis in man and mouse. Biochim. Biophys. Acta 1529, 357-373 (2000).

42. McLarren, K. W. et al. Hypomorphic temperature-sensitive alleles of NSDHL Cause CK Syndrome. Am. J. Hum. Genet. 87, 905-914 (2010).

43. Sambrook, J. \& Green, M. R. Molecular Cloning: A Laboratory Manual (Cold Spring Harbor Laboratory Press, 2012).

44. Darnet, S. \& Rahier, A. Enzymological properties of sterol-C4-methyloxidase of yeast sterol biosynthesis. Biochim. Biophys. Acta 1633, 106-117 (2003).

45. Thompson, J. D., Gibson, T. J., Plewniak, F., Jeanmougin, F. \& Higgins, D. G. The CLUSTAL_X windows interface: flexible strategies for multiple sequence alignment aided by quality analysis tools. Nucleic Acids Res. 25, 4876-4882 (1997).

46. Sali, A. \& Blundell, T. L. Comparative protein modeling by satisfaction of spatial restraints. J. Mol. Biol. 234, 779-815 (1993).

47. Benkert, P., Kunzli, M. \& Schwede, T. QMEAN server for protein model quality estimation. Nucleic Acids Res. 37, 510-514 (2009).

48. Holm, L., Kaariainen, S., Rosenstrom, P. \& Schenkel, A. Searching protein structure databases with DaliLite v.3. Bioinformatics 24, 2780-2781 (2008).

\section{Author contributions}

S.B.H., S.K., A.R., S.Ro. designed and performed experiments, analysed the data and wrote the paper, D.H., A.H., T.W., S.Re. designed and performed experiments, analysed the data and prepared figures, I.F., P.-E.I., C.V.M., J.R.L-D, C.F., J.G., H.U.N., R.R., J.A.S.,
H.Y., V.P., J.T. designed and performed experiments, analysed the data, R.J., J.Z., T.A., P.K., A.M., K.M., L.O. designed and performed the experiments, M.F., M.B. performed modelling, analysed the data and prepared figures, S.S., R.K. designed the experiments and analysed the data, C.N.P. designed the experiments, analysed the data and wrote the paper N.R.M. created the concept and provided support for this work.

\section{Additional information}

Accession codes. Crystallographic data (excluding structure factors) have been deposited with the Cambridge Crystallographic Data Centre as supplementary publication number CCDC 976241. These data can be obtained free of charge from the Cambridge Crystallographic Data Centre via www.ccdc.cam.ac.uk/data_request/cif

Supplementary Information accompanies this paper at http://www.nature.com/ naturecommunications

Competing financial interests: The authors declare no competing financial interests.

Reprints and permission information is available online at http://npg.nature.com/ reprintsandpermissions/

How to cite this article: Helliwell, S. B. et al. FR171456 is a specific inhibitor of mammalian NSDHL and yeast Erg26p. Nat. Commun. 6:8613 doi: 10.1038/ncomms9613 (2015).

(c) (i) This work is licensed under a Creative Commons Attribution 4.0 International License. The images or other third party material in this article are included in the article's Creative Commons license, unless indicated otherwise in the credit line; if the material is not included under the Creative Commons license, users will need to obtain permission from the license holder to reproduce the material. To view a copy of this license, visit http://creativecommons.org/licenses/by/4.0/ 